\title{
A Review on Improving the Quality of Perovskite Films in Perovskite Solar Cells via the Weak Forces Induced by Additives
}

\author{
Jien Yang ${ }^{1, *,+}$, Songhua Chen ${ }^{2,+}$, Jinjin Xu ${ }^{1}$, Qiong Zhang ${ }^{1}$, Hairui Liu ${ }^{1} \oplus$, Zhiyong Liu ${ }^{1}$ \\ and Mingjian Yuan ${ }^{3}$ \\ 1 College of Physics and Material Science, Henan Key Laboratory of Photovoltaic Materials, Henan Normal \\ University, Xinxiang 453007, China; jinjinxuhtu@163.com (J.X.); 15117312218@163.com (Q.Z.); \\ liuhairui1@126.com (H.L.); zyliu01@163.com (Z.L.) \\ 2 College of Chemistry and Material Science, Longyan University, Longyan 364012, China \\ songhua@iccas.ac.cn \\ 3 College of Chemistry, Nankai University, Tianjin 300071, China; yuanmj@nankai.edu.cn \\ * Correspondence: yjen@htu.edu.cn \\ + The two authors contributed equally to this paper.
}

Received: 12 September 2019; Accepted: 12 October 2019; Published: 17 October 2019

\begin{abstract}
Perovskite solar cells (PSCs) employing organic-inorganic halide perovskite as active layers have attracted the interesting of many scientists since 2009. The power conversion efficiency (PCE) have pushed certified 25.2\% in 2019 from initial 3.81\% in 2009, which is much faster than that of any type of solar cell. In the process of optimization, many innovative approaches to improve the morphology of perovskite films were developed, aiming at elevate the power conversion efficiency of perovskite solar cells (PSCs) as well as long-term stability. In the context of PSCs research, the perovskite precursor solutions modified with different additives have been extensively studied, with remarkable progress in improving the whole performance. In this comprehensive review, we focus on the forces induced by additives between the cations and anions of perovskite precursor, such as hydrogen bonds, coordination or some by-product (e.g., mesophase), which will lead to form intermediate adduct phases and then can be converted into high quality films. A compact uniform perovskite films can not only upgrade the power conversion efficiency (PCE) of devices but also improve the stability of PSCs under ambient conditions. Therefore, strategies for the implementation of additives engineering in perovskites precursor solution will be critical for the future development of PSCs. How to manipulate the weak forces in the fabrication of perovskite film could help to further develop high-efficiency solar cells with long-term stability and enable the potential of future practical applications.
\end{abstract}

Keywords: perovskite; additives; weak forces; hydrogen bon

\section{Introduction}

The ecological environment has deteriorated in recent years, which has resulted in an increasing demand for new clean and renewable energy sources. Solar energy has been recognized as almost inexhaustible and the most abundant of all natural energy resources [1,2]. Therefore, various solar cells have been developed to convert solar energy to electrical energy directly, including crystal silicon solar cells, dye-sensitized solar cells, quantum-dot solar cells and organic solar cells. However, the sophisticated processing, environmental damage and high cost of those commercial solar cells force scientists to develop new types of solar cells. Currently, the perovskite solar cell is the most promising one, with relatively low cost and high power conversion efficiency (PCE), in which 
perovskite layer plays the role of absorbing material for producing exciton. There is a long history of research on the synthesis of halide perovskites. $\mathrm{CaTiO}_{3}$ was discovered in the Ural Mountains of Russia by Gustav Rose in 1839, and perovskite was named after Russian mineralogist Lev Perovski. There is also a hybrid perovskite with a composition of $\mathrm{ABX}_{3}$, where $\mathrm{A}$ are monovalent cations $\left(\mathrm{MA}^{+}\right.$or $\mathrm{FA}^{+}$), $\mathrm{B}$ are metal cations $\left(\mathrm{Sn}^{2+}\right.$ or $\left.\mathrm{Pb}^{2+}\right)$ and $\mathrm{X}$ are halide anions $\left(\mathrm{I}^{-}, \mathrm{Br}^{-}\right.$, and/or $\left.\mathrm{Cl}^{-}\right)$[3]. Perovskite materials have excellent optical and electrical properties for outstanding performance in solar cell application, such as direct band gap, steep optical absorption edge [4,5], high charge carrier mobility [6] and long charge carrier diffusion lengths and carrier lifetimes $[7,8]$. The PCE of perovskite solar cells (PSCs) has increased from $3.8 \%$ in 2009 [9] to $25.2 \%$ in this year, becoming the fastest-advancing solar cell.

There are still some issues impeding the practical application of the perovskite solar cells, such as hysteresis [10], ionic migration [11], heavy metal lead [12] and moisture stability [13]. Tremendous effort has been devoted to overcome those challenges, for example, through interface engineering [14,15], anti-solvent doping [16,17], new perovskite materials [18,19], new device structures $[20,21]$, using additives [22], etc. With those approaches, additive engineering has been reported to slow down the crystallization rate of the perovskite crystals in solution processing. This review mainly analyzes the mechanism of the additives in perovskite precursor solvent, such as hydrogen bonding or coordination between the additive and perovskite components. In addition, the formed mesophase or the additives reacting with a certain substance during the perovskite crystallization could improve the quality of the perovskite film. The morphology of perovskite film is not only a key factor affecting the efficiency of perovskite solar cell, but is also paramount in other applications, e.g., light emitting diodes (LEDs), potential spintronics applications and so on. The mechanism for ameliorate the morphology of perovskite films with additives are mainly to slow down the crystallization rate of perovskite crystals to achieved large crystal grains, thereby realizing an improvement of PCE. The purpose of this review was to classify the main weak forces involved in the formation of the perovskite films and to provide useful information to readers working in this field.

\section{The Mechanisms of Additives}

\subsection{Hydrogen Bonds}

A hydrogen bond is a relatively weak bond that hydrogen atoms interaction with the electronegative atoms nitrogen, oxygen or fluorine. Hydrogen bond is usually weaker than ionic, covalent and metallic bonds, but plays an important role in formation of perovskite film. In a typical perovskite precursor solution, hydrogen bond formed between the hydrogen atom and the other atoms (e.g., N, O atoms), which will affect the growth of perovskite crystals and the quality of the films in finally.

Chang et al. [23] first discovered that the addition of $1 \mathrm{wt} . \%$ poly (ethylene glycol) (PEG) to a $\mathrm{CH}_{3} \mathrm{NH}_{3} \mathrm{PbI}_{3-\mathrm{x}} \mathrm{Cl}_{\mathrm{x}}$ perovskite precursor solution can solve the problem of poor coverage of the perovskite film on $\mathrm{TiO}_{2}$ as shown in Figure 1. The higher coverage of the perovskite layer reduces the possibility of direct contact between the $\mathrm{TiO}_{2}$ and the 2,2',7,7'-Tetrakis[N,N-di(4-methoxyphenyl)amino]-9, $9^{\prime}$-spirobifluorene (spiro-OMeTAD) layer, which leads to a higher open-circuit voltage $\left(V_{o c}\right)$ in a device. However, when the PEG content exceeds $1 \mathrm{wt} . \%$, the performance of a device would decrease in all aspects. This is because once the amount of PEG additive is overloaded, the charge cannot efficiently be transferred to the $\mathrm{TiO}_{2}$ nanoparticles or spiro-OMeTAD layer and will accumulate or recombine in the perovskite layer. Zhao et al. [24] reported a PEG polymer scaffold PSCs, and subsequently, the PCE exceeded 16\%. The long-chain insulating polymer dissolved in the precursor solution will be assembled into a three-dimensional (3D) scaffold when the precursor solution is spin-coated on the substrate. The formed scaffold can guarantee a uniform thickness and homogeneous morphology of the perovskite films. Therefore, the performance of the solar cell is greatly improved. 
(a)

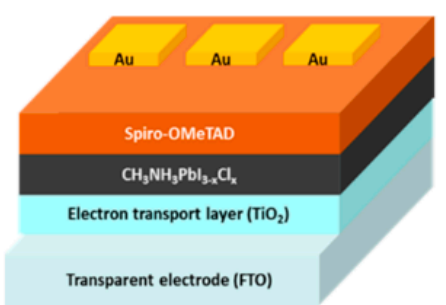

(c)

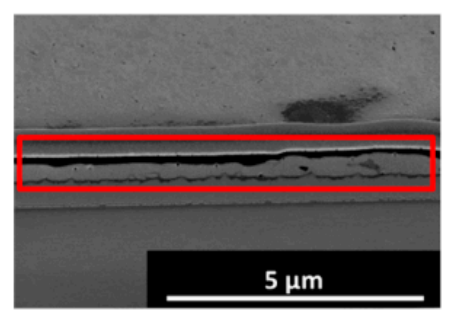

(b)

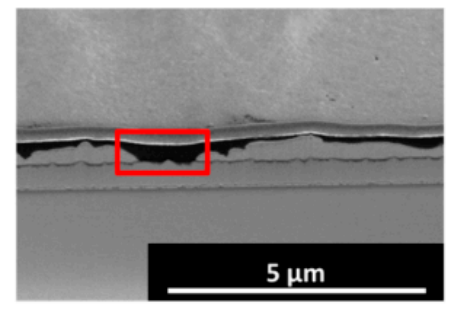

(d)

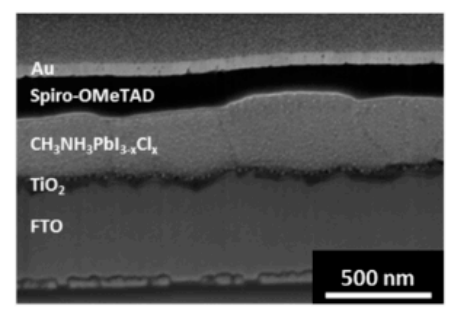

(e)

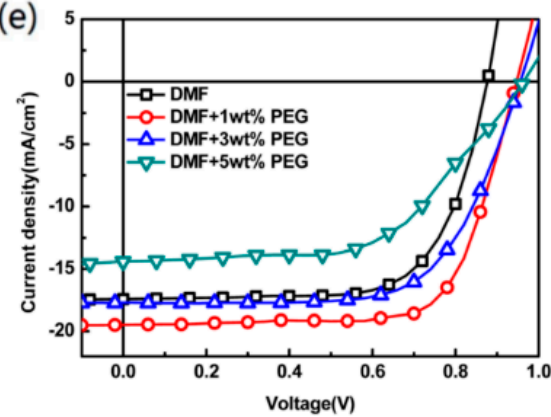

Figure 1. (a) Device architecture diagram. (b) Scanning electron microscopy (SEM) cross-section image of the pristine device. (c) SEM cross-section image of the treatment with $1 \mathrm{wt}$ \% poly (ethylene glycol) (PEG), and close-up of the image of the red box in $(\mathbf{d}, \mathbf{c})$. (e) Current density-voltage (J-V) curve for devices of varying amounts of PEG additive. Reproduced with permission from Reference [23]. Copyright 2015 American Chemical Society.

As we known, $\mathrm{PEG}$ is a hygroscopic polymer containing $\mathrm{O}$ atoms. There is a strong interaction with perovskite by hydrogen bonds with $\mathrm{H}$ atoms in $\mathrm{CH}_{3} \mathrm{NH}_{3}{ }^{+}$. Figure 2a-d show the Scanning electron microscopy (SEM) images of perovskite films without polymer scaffolds and with polymer scaffolds. This is consistent with the report from Chang. They speculated that PEG molecules are anchored on the surface of the perovskite crystallites by a hydrogen bond, as shown in Figure 2e. Another interesting finding is that PEG has a strong hygroscopicity and a binding effect with methylammonium iodide (MAI), which can protect perovskite from being decomposed. The enhancement of device stability is mainly due to the forces of hydrogen bond between MAI and PEG. The MAI molecule is anchored by a nearby PEG molecule. After annealing, $\mathrm{MAPbI}_{3}$ phase will be generated by the reacts of $\mathrm{PbI}_{2}$ and MAI. The instantaneous decomposition regeneration mechanism in Figure $2 \mathrm{~g}$ explains the rapid self-healing process in perovskite films with PEG scaffolds. They further tried PEG and [6,6]-phenyl- $\mathrm{C}_{61}$-methylbutyrate $\left(\mathrm{PC}_{61} \mathrm{BM}\right)$ dual additives in the perovskite solution [25]. Among them, PEG still plays a role in ameliorating the film morphology and device stability.

Similarly, polyvinylpyrrolidone (PVP) can also serve as an additive for enhancing the stability of the PSCs by forming hydrogen bonds. Nakamura et al. [26] proposed that doping PVP in the perovskite precursor solution can produce a perovskite film with a smoother surface morphology and minimum crystallite size in ambient air. The production of translucent perovskite films also requires smaller grain sizes [27]. Translucent perovskite film (50-100 nm) is a key device for window applications in zero-energy building technology [28,29]. The mechanism of PVP as an additive to control the crystal size and enhance device stability is shown in Figure 3a-e. The hydrogen bonds formed between $\mathrm{O}$ atoms in $\mathrm{PVP}$ and $\mathrm{H}$ atoms of $\mathrm{CH}_{3} \mathrm{NH}_{3}{ }^{+}$in the perovskite can protect the minimum perovskite crystals. As a result, the stability of the PVP-doped device further increases. 

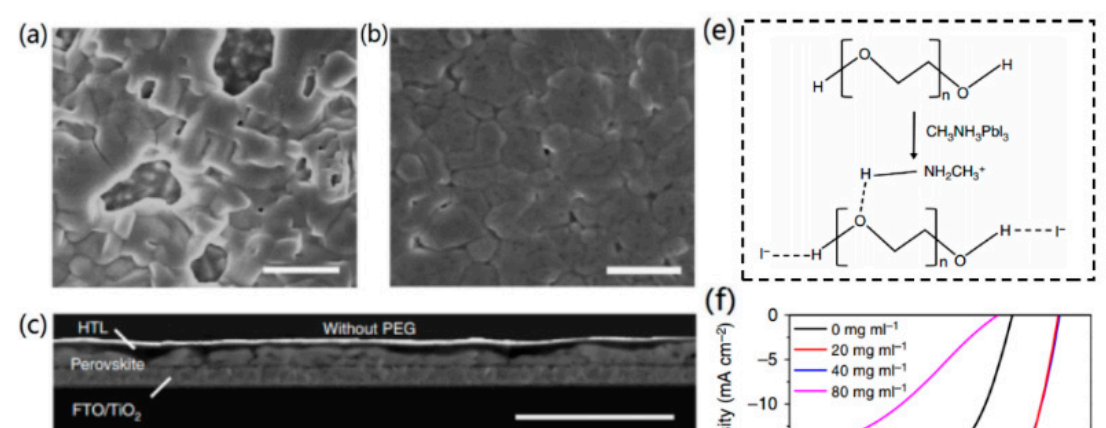

(d)
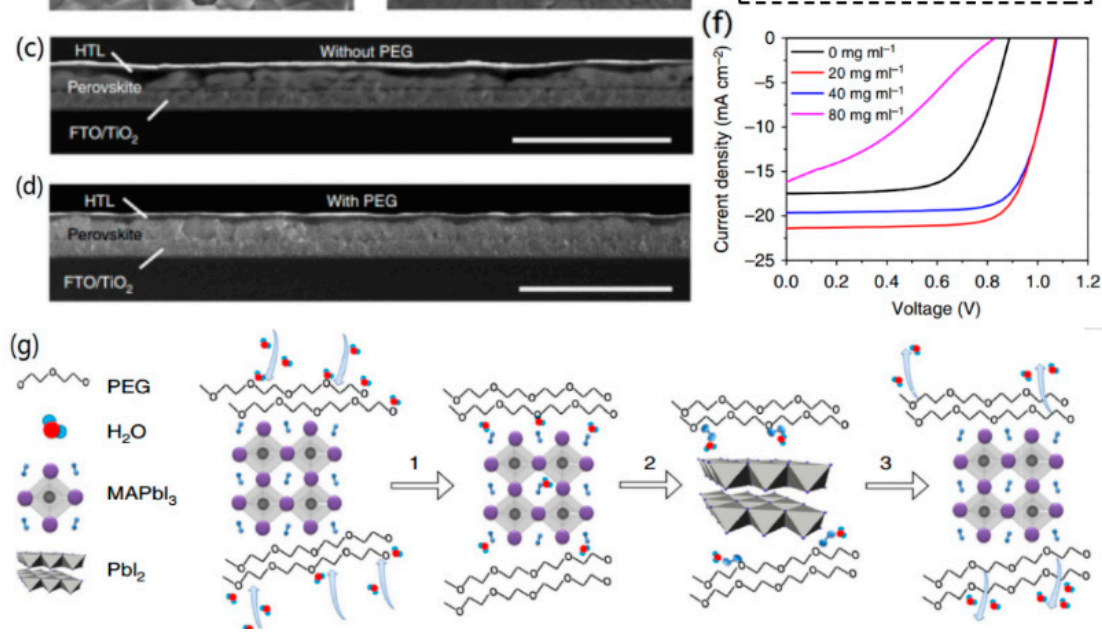

Figure 2. Top view SEM image of perovskite film (a) without PEG and (b) with PEG. (scale bar, $1 \mathrm{~mm}$ ). (c) Cross-sectional SEM images of perovskite solar cells without PEG and (d) PEG scaffolds. (scale bar, $3 \mathrm{~mm}$ ). (e) Schematic diagram of the formation of a hydrogen bond between a PEG molecule and $\mathrm{MAPbI}_{3}$. (f) J-V curves for devices with different PEG concentrations. (g) Schematic: (1) water uptake on perovskite; (2) perovskite hydrolyzed by water to $\mathrm{PbI}_{2}$ and $\mathrm{MAIH}_{2} \mathrm{O}$; (3) after evaporation of the water, the PEG-inhibited methylammonium iodide (MAI) reacts with the nearby $\mathrm{PbI}_{2}$ to form perovskite. Reproduced with permission from Reference [24]. Copyright 2016 Nature Publishing Group.

In addition, the polymer can be used as an additive to stabilize the perovskite crystals to prevent moisture degradation. Recently, Kim et al. [30] selected non-electroactive polymer polyethylene oxide (PEO) as an additive to make flexible devices and optimized the concentration of PEO. PEO additive acts as a crystallization inhibitor by physically interfering with crystallization and improving processability, thereby producing a large-area defect-free perovskite film. The oxygen atom in the PEO molecule can form a hydrogen bond with the methylammonium cation $\left(\mathrm{MA}^{+}\right)$in the perovskite component, hindering the formation of hydrate under hydration conditions. As shown in Figure $4 \mathrm{a}$, in a dry environment, equipment with PEO additives exhibited similar performance to equipment without the added polymer. However, it is apparent from Figure $4 \mathrm{~b}$ that the difference between the equipment with and without the PEO additive becomes superficial on wet days. To investigate the origin of these differences, we analyzed these films using SEM. As expected, there was no significant difference in the grain size of the film deposited at low humidity, and the difference in grain size of high humidity was more pronounced. This is because PEO is capable of forming stable coordination bonds with positive ions and generating a stable five-membered ring structure. The hydrophobic ethylene group on the surface of the film also prevents the penetration of water molecules, again reducing the negative effects of humidity. 
(a)

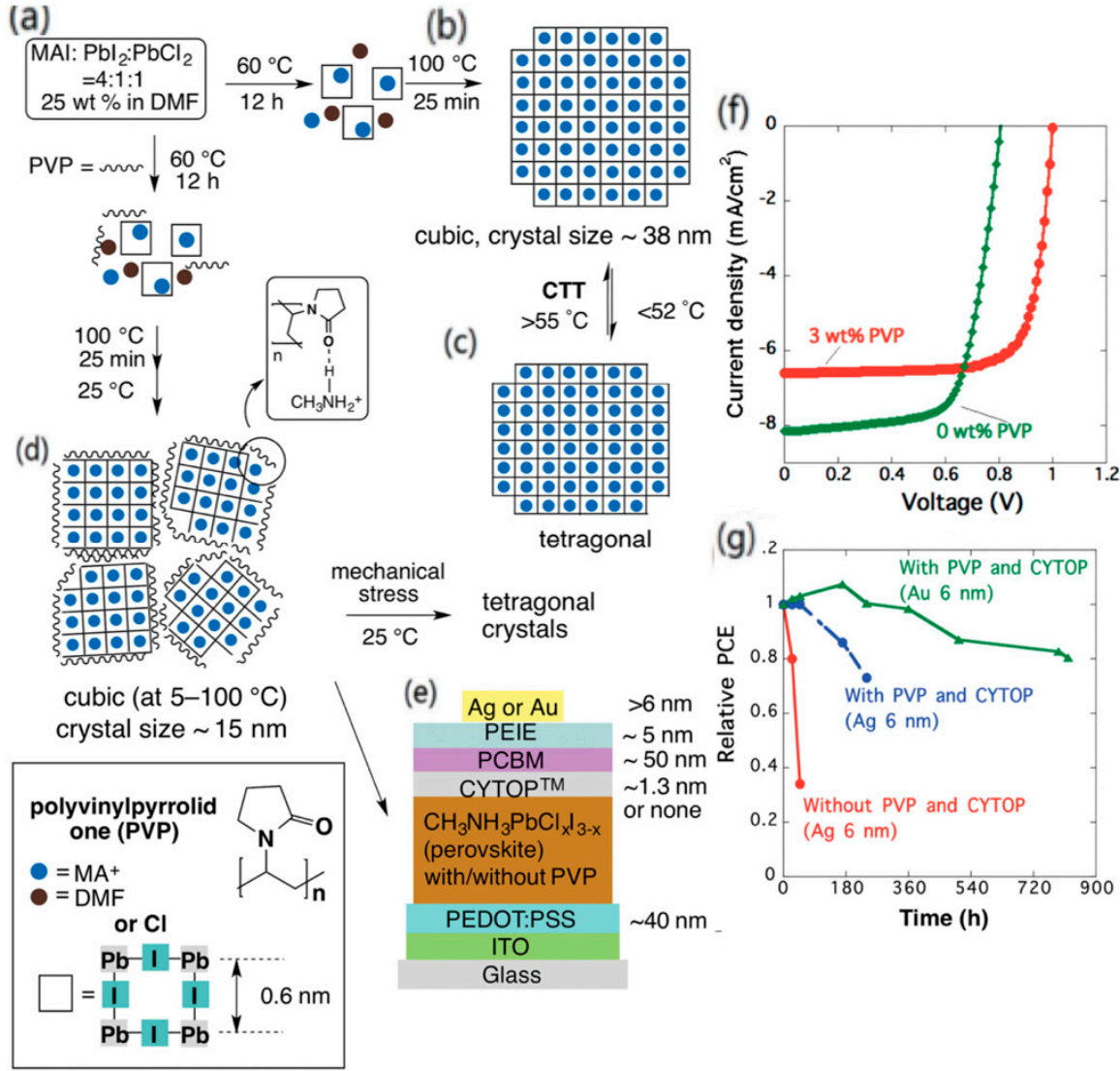

Figure 3. (a) Preparation of a precursor solution with or without polyvinylpyrrolidone (PVP). (b) PVP-free perovskite prepared at $100{ }^{\circ} \mathrm{C}$, and (c) quadrilateral PV formed at $<52{ }^{\circ} \mathrm{C}$. Cubic to quadrilateral transition $=\mathrm{CTT}$. (d) Perovskite synthesized in the presence of $3 \mathrm{wt} . \% \mathrm{PVP}$ at $100{ }^{\circ} \mathrm{C}$. (e) Schematic representation of the translucent solar cell of this study. (f) J-V characteristic curve of the device. (g) Stability testing of equipment. Under humidity control, the air temperature is $22-25{ }^{\circ} \mathrm{C}$, and the relative humidity is $24-30 \%$ [26]. Reproduced with permission from Reference [26]. Copyright 2016 Wiley-VCH.

It is interesting that bifunctional molecules have also been used as templates to direct nucleation or crystal growth. Mei et al. [31] reported that (5-AVA) $)_{x}(\mathrm{MA})_{1-\mathrm{x}} \mathrm{PbI}_{3}$ perovskite can be obtained by using 5-ammoniumvaleric acid (5-AVA) additive. The doped perovskite film has a better morphology on the $\mathrm{TiO}_{2}$ surface and a lower defect concentration, resulting in improved conversion efficiency. Before that, Mercier et al. reported the effect of 4-ammonium-butyric acid (4-ABA) additive on the crystal structure of perovskite; that is, the ABA molecules form linear hydrogen bond chains [32]. 5-AVA affects the crystal growth of $(5-\mathrm{AVA})_{\mathrm{x}}(\mathrm{MA})_{1-\mathrm{x}} \mathrm{PbI}_{3}$ by the hydrogen bond between $\mathrm{COOH}$ groups and $\mathrm{NH}_{3}{ }^{+}$ groups. The $\mathrm{COOH}$ groups of 5-AVA anchors monolayers of amino acids to the surface of mesoporous $\mathrm{TiO}_{2}$ and $\mathrm{ZrO}_{2}$ films by cooperative binding with exposed $\mathrm{Ti}$ or $\mathrm{Zr}$ ions. In this state, the terminal $-\mathrm{NH}_{3}{ }^{+}$group of 5 -AVA faces the perovskite and thus serves as a nucleation site. The optimized device showed the PCE of $11.6 \%$ with short-circuit current density $\left(J_{s c}\right), V_{o c}$ and fill factor (FF) of $21.1 \mathrm{~mA} \mathrm{~cm}^{-2}$, $843 \mathrm{mV}$ and 0.65 , respectively (Figure 5b). For 5-AVA-doped PSCs, the slope of the $J V$ curve at the open circuit voltage is steeper than for $\mathrm{MAPbI}_{3}$, indicating that the resistance of the doped device is reduced. In brief, the better surface contact had been ensured between perovskite and $\mathrm{TiO}_{2}$ by the hydrogen bonds between the $\mathrm{COOH}$ groups and $-\mathrm{NH}_{3}{ }^{+}$groups (Figure $5 \mathrm{c}, \mathrm{d}$ ). Recently, Lin et al. [33] also explored the role of 5-AVA as a perovskite precursor solution additive. They found that unpackaged devices with $\mathrm{AVA}-\mathrm{MAPbI}_{3}$ showed a 40-fold longer life than devices with $\mathrm{MAPbI}_{3}$ in ambient air. This is because AVA-MAPbI 3 also has the effect of inactivating surface defect sites. 

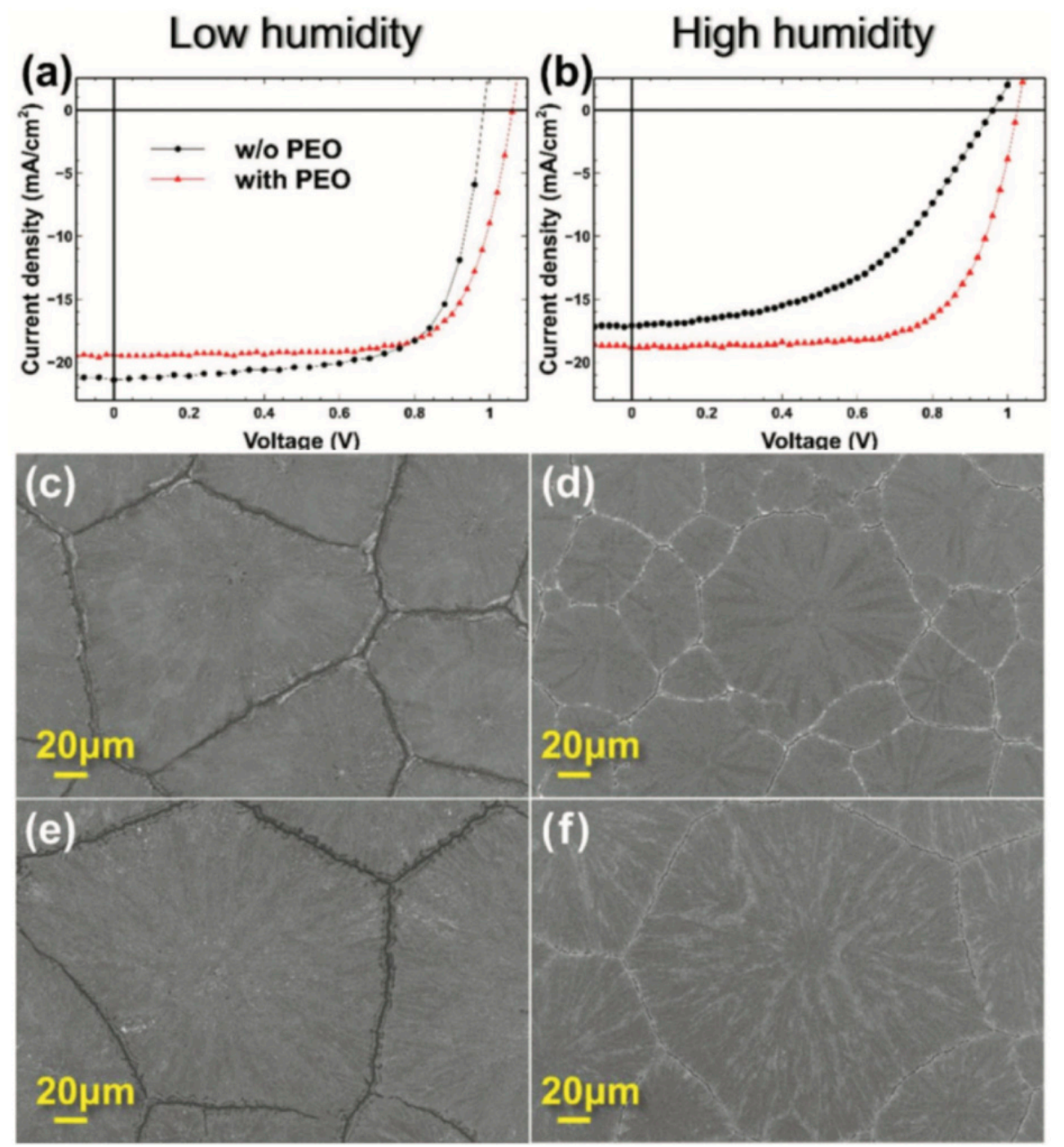

Figure 4. J-V curve with and without polyethylene oxide (PEO) in (a) low humidity and (b) high humidity environments. (c-f) SEM images of perovskite films on Indium Tin Oxide (ITO)/Poly (3,4-ethylenedioxythiophene)/poly (styrenesulfonate) (PEDOT:PSS) substrates with and without PEO at low humidity and high humidity [30]. Reproduced with permission from Reference [30]. Copyright 2019 Wiley-VCH.

One additive that has the effect of cross-linking adjacent perovskite crystals is $\mathrm{PbAc}_{2}$. Tang et al. [34] found that $\mathrm{PbAc}_{2}$ can act as a cross-linking agent to stabilize the perovskite mesophase by forming strong hydrogen bonds. In addition, $\mathrm{PbAc}_{2}$ can produce $\mathrm{PbI}_{2}$ in the perovskite film, which will passivate defects at the grain boundaries. Although $\mathrm{PbAc}_{2}$ has been used as a lead source for the manufacture of pinhole-free and ultra-smooth perovskite films, it has never previously been reported as an additive for enhancing the crystallization of perovskite films. The efficiency of adding only $3 \%$ of $\mathrm{PbAc}_{2}$ is relatively improved by about $10 \%$, and the device stability is also greatly improved. As shown in Figure $6 \mathrm{~b}$, the stable output PCE of the two devices with and without $\mathrm{PbAc}_{2}$ was $18.50 \%$ and $16.13 \%$, respectively. This is because $\mathrm{PbAc}_{2}$ is introduced into the precursor solution to form a strong hydrogen bond. As shown in Figure $6 \mathrm{f}$, hydrogen bonding can be formed by the interaction between $\mathrm{MA}^{+}$and $\mathrm{O}$ in $\mathrm{PbAc}_{2}$. This hydrogen bonding causes $\mathrm{PbAc}_{2}$ to act as a crosslinking agent in the mesophase to enhance its stability. As shown in Figure $6 \mathrm{~g}$, the absorption peak having a wave number of $1580 \mathrm{~cm}^{-1}$ belongs to the $\mathrm{N}-\mathrm{H}$ bond of the $\mathrm{MA}^{+}$group. For perovskite films containing $3 \% \mathrm{PbAc}_{2}$, the N-H bond was red shifted to $1571 \mathrm{~cm}^{-1}$, demonstrating that hydrogen bonding affects adjacent N-H bonds by reducing its vibration frequency. 

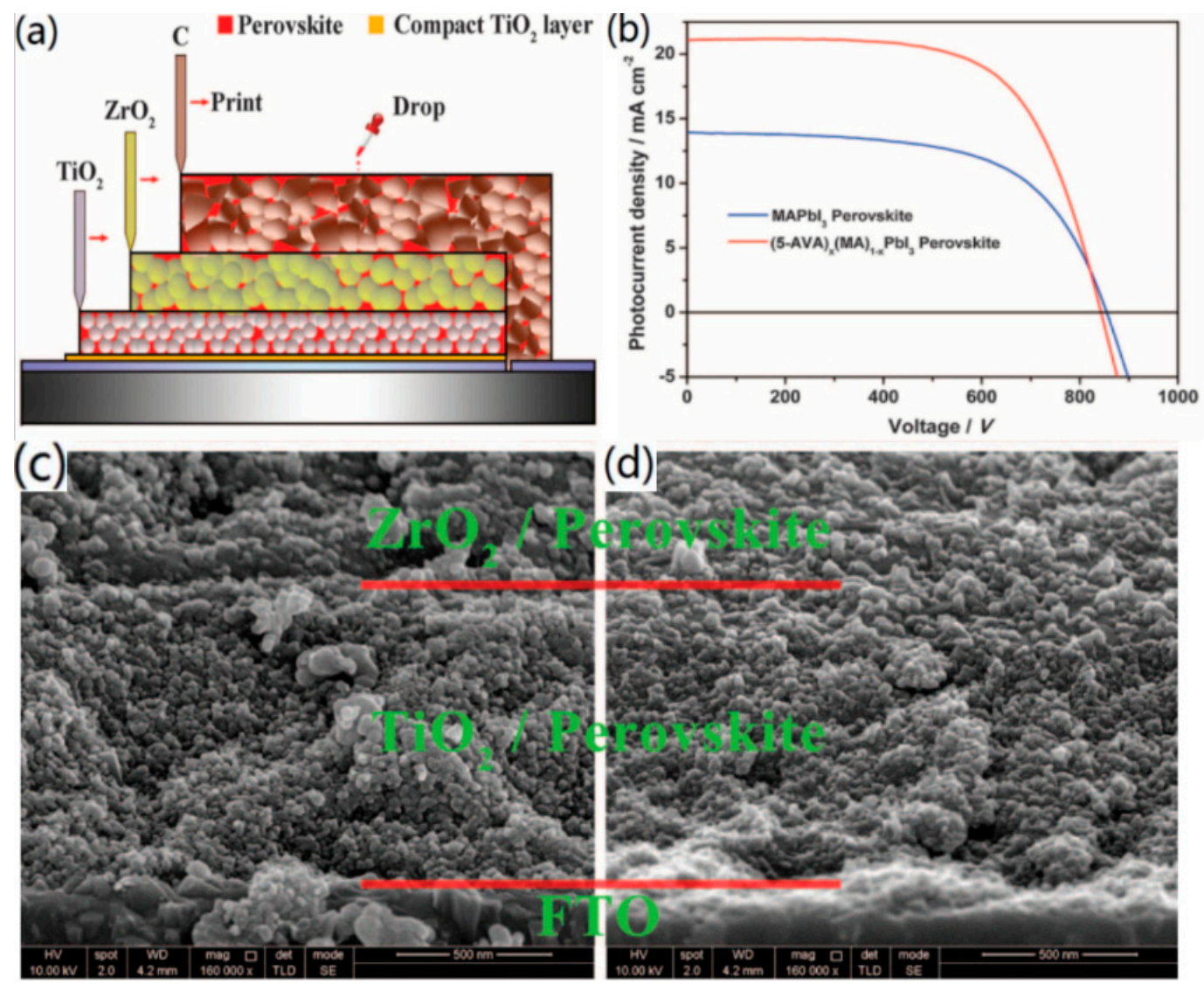

Figure 5. (a) Schematic showing a cross section of a perovskite solar cell. (b) J-V curve of the device at $100 \mathrm{~mW} \mathrm{~cm}{ }^{-2}$ intensity. SEM images of perovskite solar cell cross sections based on $\mathrm{MAPbI}_{3}(\mathrm{c})$ and based on (5-AVA) $)_{X}(\mathrm{MA})_{1-\mathrm{x}} \mathrm{PbI}_{3}(\mathrm{~d})$. Reproduced with permission from Reference [31]. Copyright 2014 the American Association for the Advancement of Science.

(a)

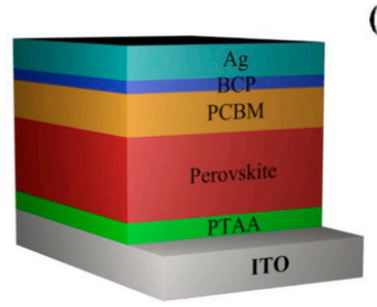

(d)

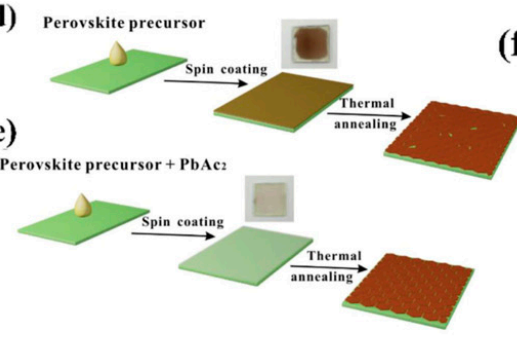

(b)

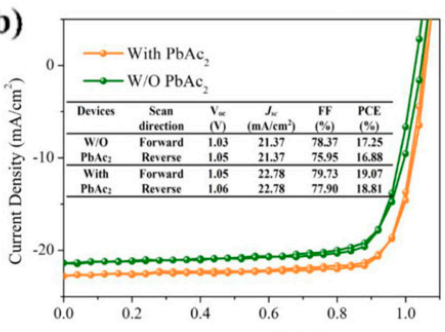

(f)
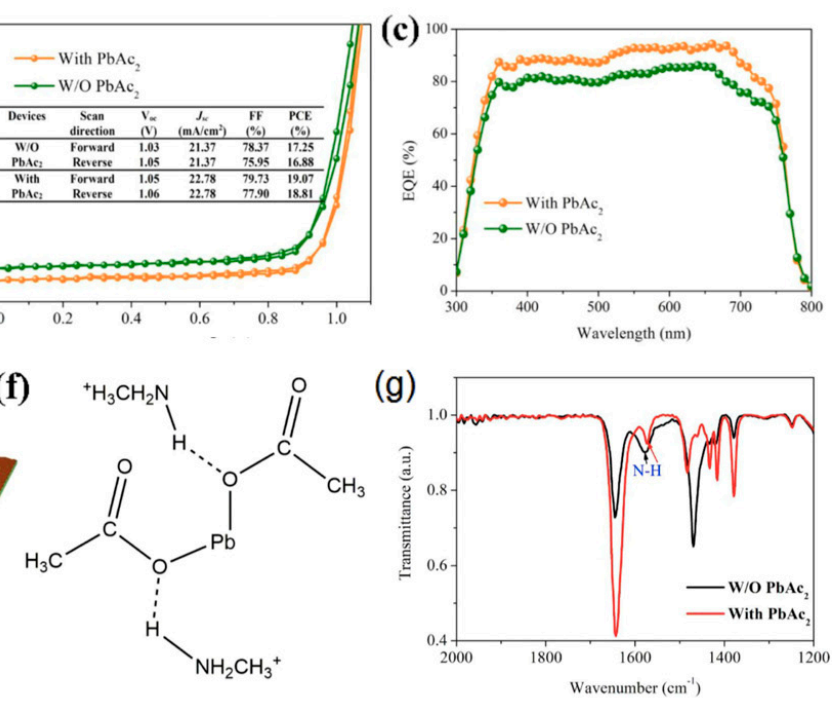

Figure 6. (a) Schematic diagram of the inverted device. (b) J-V curve and (c) External quantum effciency (EQE) curve of PSC with or without $\mathrm{PbAc}_{2}$ added in device fabrication. Schematic representation of film preparation: (d) contains no $\mathrm{PbAc}_{2}$ and (e) $\mathrm{PbAc}_{2}$ in the precursor solution. (f) Schematic diagram of hydrogen bond formation between $\mathrm{PbAc}_{2}$ and MAI. (g) Fourier Transform Infra-Red (FTIR) spectra of the perovskite film containing no $\mathrm{PbAc}_{2}$ in the precursor [34]. Reproduced with permission from Reference [34]. Copyright 2018 Wiley-VCH. 
Recently, Zhu et al. [35] found that ethylamine alcohol chloride $(\mathrm{EA} \cdot \mathrm{HCl})$ was introduced into the perovskite film to effectively passivate the defect state. As shown in Figure 7a, EA·HCl has two groups: a hydroxyl group $(-\mathrm{OH})$ and an ammonium group $\left(-\mathrm{NH}_{3}\right)$, which interact with the halogen in $\mathrm{MAPbI}_{\mathrm{x}} \mathrm{Cl}_{3-\mathrm{x}}$ to form a hydrogen bond that inhibits ion migration. Bifunctional groups can passivate defects by generating hydrogen bonding interactions or by coordinating with under-coordinated iodide ions to immobilize the halide anions of the perovskite. The perovskite grain size and film coverage were improved, and Figure 7d,e shows a top-view SEM image of the perovskite film without and on the Poly (3,4-ethylenedioxythiophene)/poly (styrenesulfonate) (PEDOT:PSS) coated Indium Tin Oxide(ITO) glass substrate. The final device performance also demonstrates that the EA. $\mathrm{HCl}$ additive can be introduced into the perovskite film by a simple one-step solution process, which increases the open circuit voltage from $0.87 \mathrm{~V}$ to $0.92 \mathrm{~V}$ and increases the device efficiency from $14.52 \%$ to $16.97 \%$. (Figure 7c).

(a)
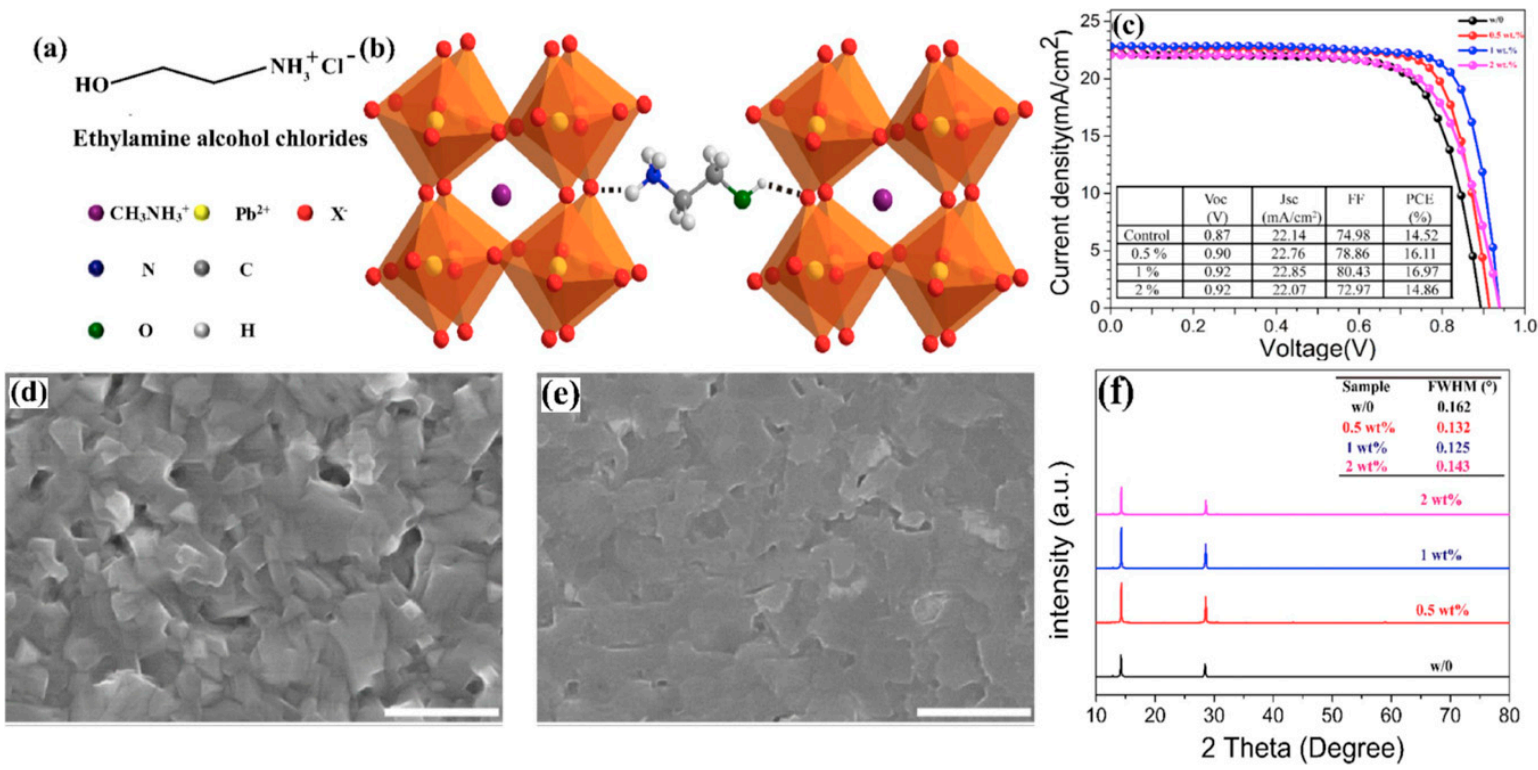

Figure 7. (a) Chemical structure of ethylamine chloride. (b) $-\mathrm{OH}$ and $-\mathrm{NH}_{3}$ in $\mathrm{EA} \cdot \mathrm{HCl}$ interact with the halogen anion in $\mathrm{MAPbI}_{\mathrm{x}} \mathrm{Cl}_{3-\mathrm{x}}$. (c) J-V curves for different levels of $\mathrm{EA} \cdot \mathrm{HCl}$ perovskite solar cells. SEM image of perovskite film: (d) without $1 \mathrm{wt} . \% \mathrm{EA} \cdot \mathrm{HCl}$ and (e) with $1 \mathrm{wt} . \% \mathrm{EA} \cdot \mathrm{HCl}$. (f) X-ray diffraction (XRD)of perovskite films having different contents of $\mathrm{EA} \cdot \mathrm{HCl}$ additives [35]. Reproduced with permission from Reference [35]. Copyright 2019 Elsevier B.V.

\subsection{Coordinate Covalent Bond}

The coordinate covalent bond, also known as a dative bond or coordinate bond, is pervasive. In all metal aquo-complexes, the bonding between water and the metal cation is described as a coordinate covalent bond. Metal-ligand interactions in most organometallic compounds and most coordination compounds are described similarly.

Tripathi et al. [36] used amine-based polymer poly[9,9-bis (30-( $N, N$-dimethylaminol-propyl)-2,7 -fluorene)-alt-2,7-(9,9-dioctylfluorene)] (PFN-P1) as a surfactant to product PSCs take excellent performance and stability. The authors used a cationic derivative (PFN-P2) on the cathode side, while the neutral form PFN-P1 served as an additive for the perovskite layer (Figure 8b-d). The ability of cationic or halogenated PFN derivatives to improve the electron selectivity at the cathode interface has been demonstrated [37,38] The PFN-P1 is spin coated onto PEDOT:PSS firstly, and $\mathrm{PbI}_{2}$ solution is spin-coated on top, subsequently. Since PFN-P1 is soluble in N,N-Dimethylformamide(DMF), it can dissolve in the $\mathrm{PbI}_{2}$ solution immediately. The coordinate covalent bond is formed between the nitrogen lone electron pair in PFN-P1 and $\mathrm{Pb}^{2+}$, and makes PFN-P1 act as a surfactant. From Figure $8 \mathrm{e}-\mathrm{h}$, it can be seen that the grain size of perovskite on PEDOT:PSS varies from 100 to $480 \mathrm{~nm}$, while the 
PFN-P1-doped film has an almost uniform grain size over the entire surface. The PFN-P1 layer flattens the surface and suppresses irregular crystallization of the $\mathrm{PbI}_{2}$ layer, thereby promoting more uniform crystallization. Figure $8 \mathrm{i}$ depicts the J-V characteristics of both devices. The device without PFN-P1 had a PCE of $12.0 \%$, while the device with PFN-P1 had a superior PCE of $13.2 \%$. The efficiency improvement of PFN-P1 based devices is mainly due to the higher $V_{o c}$ and shunt resistance $\left(R_{s h}\right)$, while $J_{s c}$ and the $F F$ of devices remained mostly unchanged. The increase in $V_{o c}$ is attributable to the reduction of charge carrier recombination at the interface, and the high $R_{s h}$ means that charge recombination is suppressed effectively. Moreover, owing to the passivation effect of the separation and accumulation of PFN-P1 molecules at the grain boundary [39], the stability of the device also greatly improved.

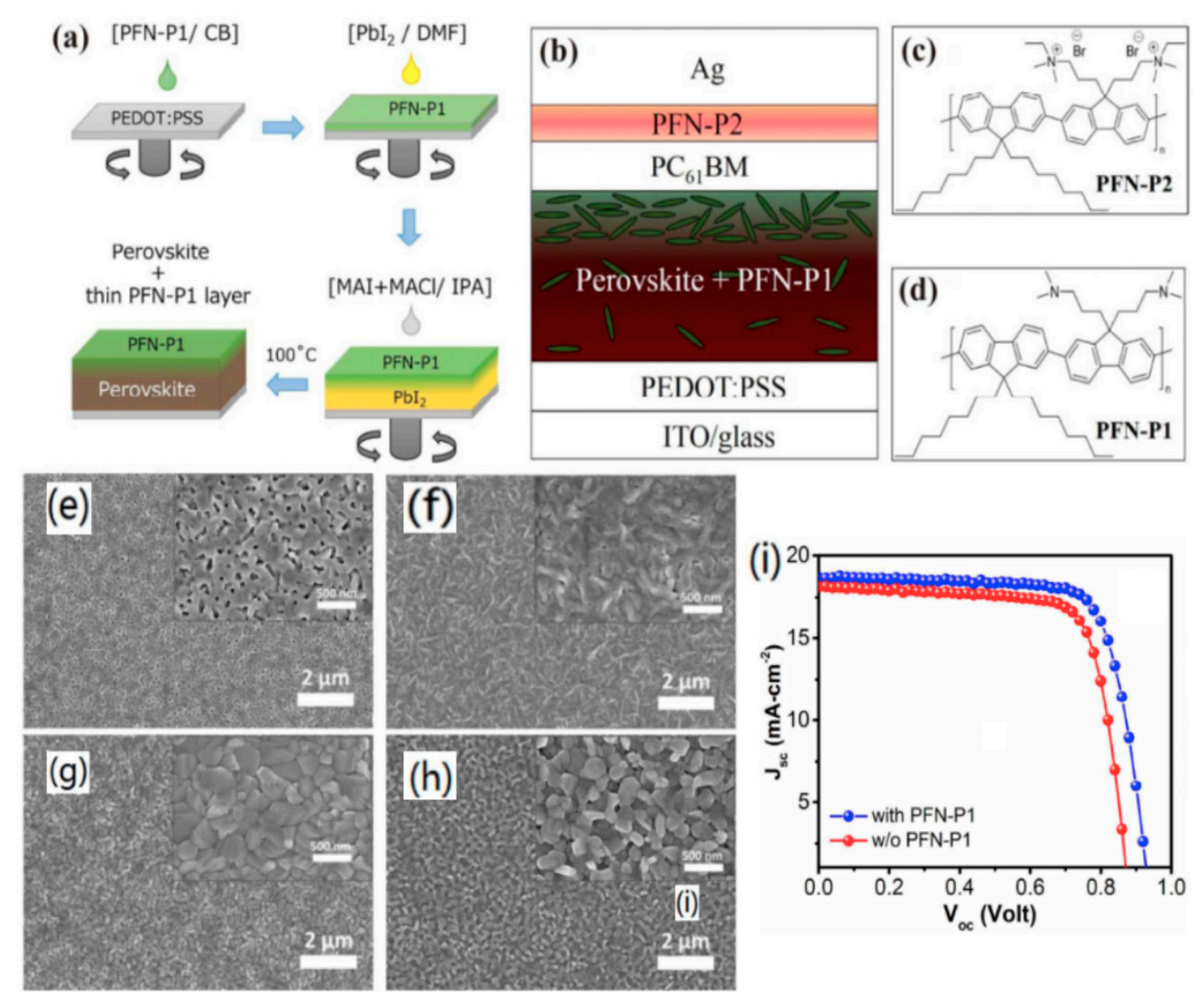

Figure 8. (a) A perovskite doped with poly [9,9-bis (30-( $N, N$-dimethylaminol-propyl)-2,7-fluorene)-alt -2,7-(9,9-dioctylfluorene)] (PFN-P1) formed by a spin coating method. (b) Schematic diagram of the device structure. (c,d) are the chemical structures of PFN-P2 and PFN-P1, respectively. (e) $\mathrm{PbI}_{2}$ membrane without PFN-P1, (f) $\mathrm{PbI}_{2}$ membrane without PFN-P1, (g) perovskite membrane without PFN-P1 and (h) perovskite without a PFN-P1 Plane SEM image of the film. (i) J-V curve. Reproduced with permission from Reference [36]. Copyright 2016 American Chemical Society.

Methyl formate (MAF) had been employed to produce higher quality crystalline perovskite films, resulting from $\mathrm{HCOO}$-interacts with $\mathrm{Pb}^{2+}$ and then slows the crystal growth of perovskite. Seo et al. proposed an ionic liquid (IL)-driven crystallization mechanism as a new strategy for the preparation of high-efficiency perovskite solar cells. If a small amount of ionic liquid (IL) is added to the precursor solution, it remains in the perovskite structure after the annealing process [40]. Figure 9a shows the chemical structure of MAF and MAI. They have the same cation (methylammonium) and a different counter anion formate $\left(\mathrm{HCOO}^{-}\right)$or iodide $\left(\mathrm{I}^{-}\right)$. The mechanism is depicted in Figure $9 \mathrm{~b}$ : (1) $\mathrm{HCOO}^{-}$ and $\mathrm{Pb}^{2+}$ are coordinate in solution and in the early stages of crystal growth; (2) when annealing to $100{ }^{\circ} \mathrm{C}, \mathrm{HCOO}^{-}$and $\mathrm{Pb}^{2+}$ is replaced by $\mathrm{Pb}^{2+}$ and $\mathrm{I}^{-}$gradually; (3) the $\mathrm{HCOO}^{-}$and $\mathrm{Pb}^{2+}$ coordination 
is replaced by $\mathrm{Pb}^{2+}$ and I- completely, and the MAF is located on the surface of the perovskite crystal. Therefore, crystal growth is slowed down with the presence of MAF, while slower crystal growth results in the larger grain size. Figure $9 \mathrm{~b}$ are SEM images of a perovskite structure with MAF and without MAF having average grain sizes of 325 and $170 \mathrm{~nm}$, respectively. Large grains can pass through the entire thickness of the perovskite structure to form a local single crystal device. Charge transfer through a single crystal is much faster than that in polycrystalline semiconductor. [41,42] Figure $9 \mathrm{~d}$ shows a $J-V$ curve with and without MAF. MAF-doped PSCs demonstrated an excellent $J_{s c}=23 \mathrm{~mA} / \mathrm{cm}^{2}$, which corresponds well with the above hypothesis.
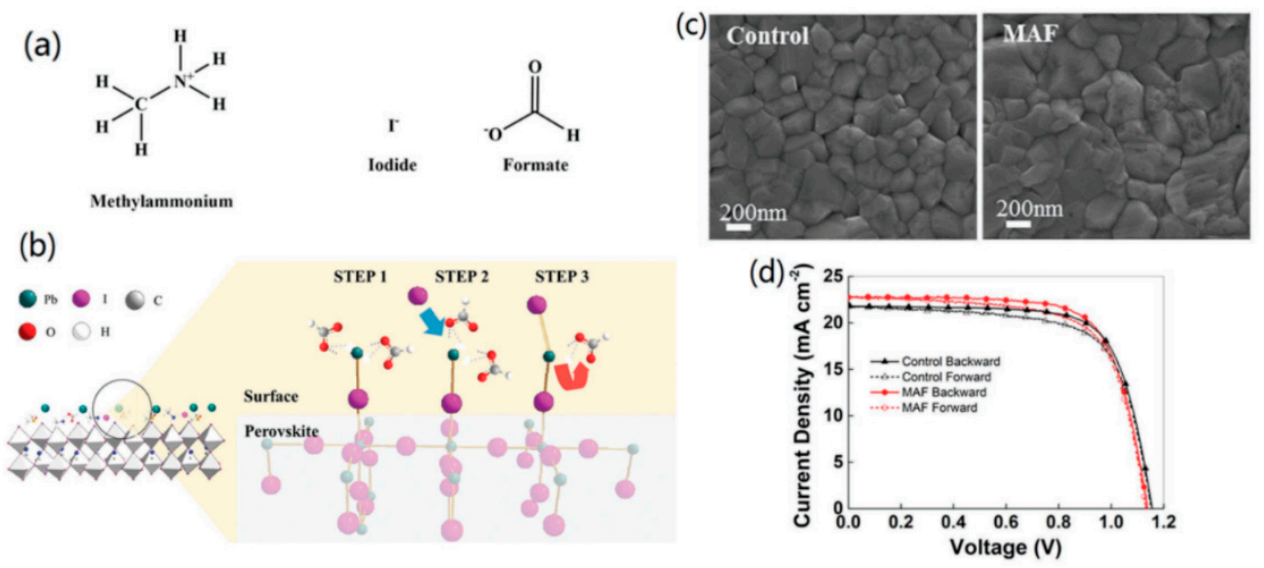

Figure 9. (a) Molecular structure of methyl ammonium iodide and formic acid. (b) Schematic representation of the growth of perovskite crystals controlled by formate anions. (c) A top view SEM image of the perovskite film. (d) J-V curve of the device. Reproduced with permission from Reference [40]. Copyright 2016 Wiley-VCH.

Metal ions play important roles in improving the quality of perovskite films as precursor solution additives. Chu et al. incorporated a series of alkali metal halide $(\mathrm{NaCl}, \mathrm{KCl}, \mathrm{LiCl})$ into the $\mathrm{PbI}_{2}$ precursor solution to adjust the morphology of the $\mathrm{PbI}_{2}$ film [43]. These halogenated additives can chelate with $\mathrm{Pb}^{2+}$ during film formation, facilitating the growth of the crystals. A significant improvement in perovskite film crystallinity has been obtained by adopting the two-step processing to adjust the morphology of $\mathrm{PbI}_{2}$ film. The large crystal size be formed with the presence of the alkali metal halide additives results in greatly improved PCE and device stability of the planar heterojunction PSCs. Figure 10a-d show the SEM images of spin-coated $\mathrm{PbI}_{2}$ films with and without additives; Figure 10e-h show the perovskite films with and without additives. In the two-step processing, the quality of the perovskite film depends on the quality of the precursor $\mathrm{PbI}_{2}$ film greatly. The optimized film formation process can not only improve device efficiency, but also significantly reduce photocurrent hysteresis (Figure 10j). As shown in Figure 10i, the highest PCE (15.08\%) was achieved with a device doped with $0.75 \% \mathrm{KCl}, J_{s c}=19.42 \mathrm{~mA} / \mathrm{cm}^{2}, V_{o c}=1.04 \mathrm{~V}, F F=0.74$. Devices fabricated using $1 \% \mathrm{NaCl}$ as an additive also exhibited improved device performance: $\mathrm{PCE}=12.77 \%$. The additive of $\mathrm{LiCl}$ reduces the performance of the device at all concentrations. This is due to the high sensitivity for oxygen and moisture of $\mathrm{Li}^{+}$. In summary, devices fabricated using $\mathrm{KCl}$ as an additive provide the best performance. These alkali metal halide additives act as electrically active impurities can passivate the grain boundary and interface states, thereby creating and disassociating the effective charge in the perovskite film [44]. 

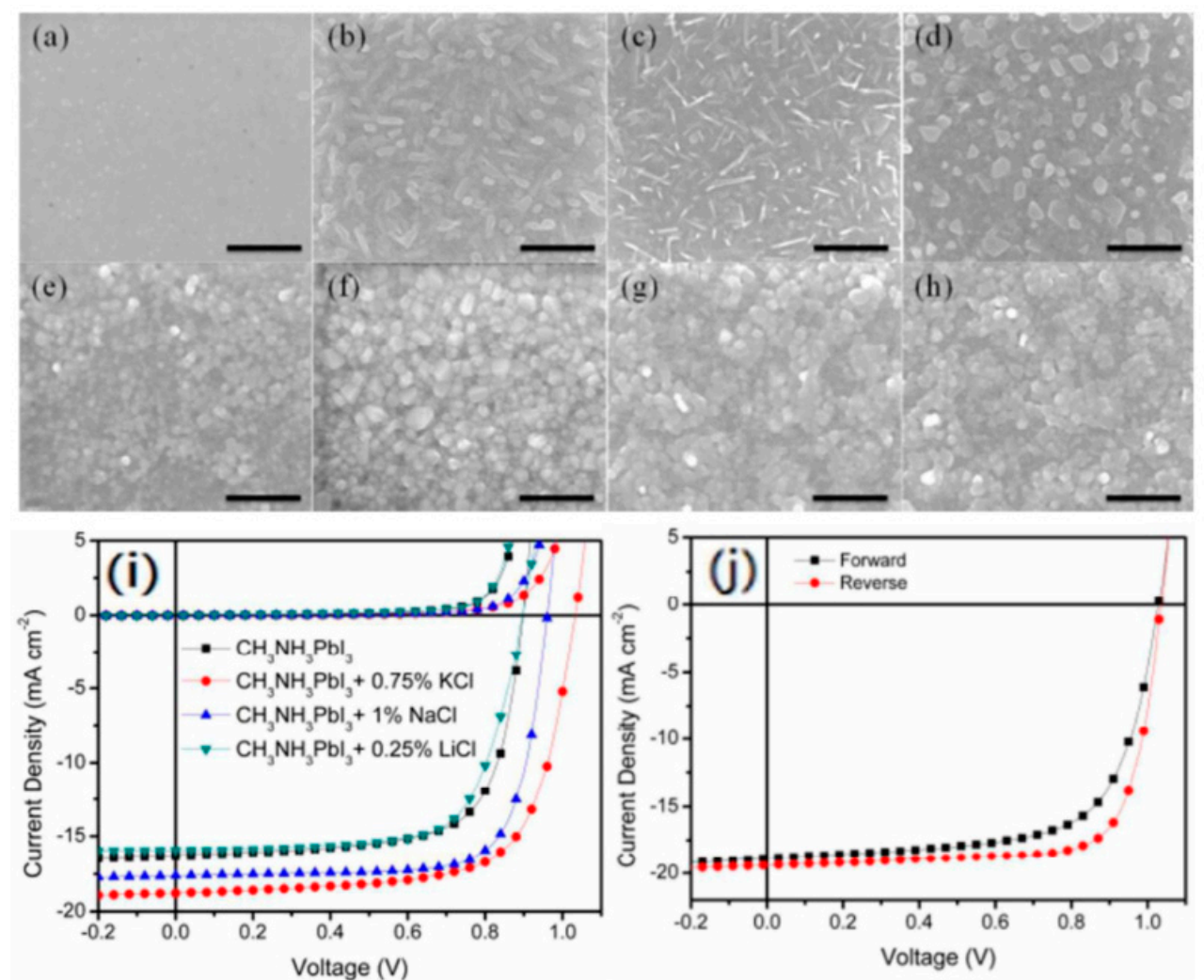

Figure 10. A top SEM image of (a-d) $\mathrm{PbI}_{2}$ film and (e-g) perovskite film prepared as (a,e) without any additives and containing $(\mathbf{b}, \mathbf{f}) \mathrm{KCl},(\mathbf{c}, \mathbf{g}) \mathrm{NaCl}$ and $(\mathbf{d}, \mathbf{h}) \mathrm{LiCl}$ as an additive to the salt (scale bar: $2 \mu \mathrm{m}$ ). J-V characteristic curve: (i) photo and dark current. (j) Effect of scanning direction on the performance of perovskite solar cells prepared with $\mathrm{KCl}$ as an additive [43]. Reproduced with permission from Reference [43]. Copyright 2016 Royal Society of Chemistry.

Potassium iodide (KI) and potassium triiodide complex $\left(\mathrm{KI}_{3}\right)$ are useful inorganic additives for the perovskite solution. Zhang et al. prepared a $\mathrm{KI}_{3}$ additive solution by dissolving equimolar amounts of KI and $\mathrm{I}_{2}$ in dimethyl sulfoxide (DMSO) [45]. They fabricated the PSCs using the $\mathrm{KI}_{3}$ additive with the method of gas-quenching. Due to the halide exchange and defect passivation caused by $\mathrm{I}_{2}$ provided by the $\mathrm{KI}_{3}$ complex, the surface morphology of the deposited perovskite film was changed significantly shown in the SEM of Figure 11a-c. As shown in Figure 11d, the (220) peak of the KI sample shifted towards lower angle compared to the control sample, indicating that iodine occupied the interstitial position resulting in lower angle shift. The $\mathrm{KI}_{3}$ sample showed a larger shift than the KI sample, indicating an even larger lattice constant resultant in the film. Due to the reduced non-radiative recombination, samples with a mixture of $\mathrm{KI}_{3}$ additives or $\mathrm{KI}$ and $\mathrm{KI}_{3}$ additives exhibited slower decay and longer life than KI and control samples. (Figure 11e) The study also found that KI and $\mathrm{KI}_{3}$ additives can significantly enhance device stability. This is due to the hydrolysis of DMF that occurs during the aging process, which consumes $\mathrm{MA}^{+}$during the formation of dimethyl formate, so the amount of $\mathrm{MA}^{+}$used after aging is reduced. However, when the $\mathrm{KI}_{3}$ complex is present in the precursor, $\mathrm{MA}^{+}$does not decrease due to I3-bonding with the $\mathrm{MA}^{+}$cation, and it is possible to form a $\mathrm{MAI}_{3}$ complex that stabilizes the precursor solution. Finally, the best performing device with $\mathrm{KI}: \mathrm{KI}_{3}=7: 3$ additive achieved $21.3 \%$ PCE in reverse scan, $21.0 \%$ in forward scan, showing negligible current density - voltage $(J V)$ The hysteresis of the characteristic is shown in Figure 11f. 

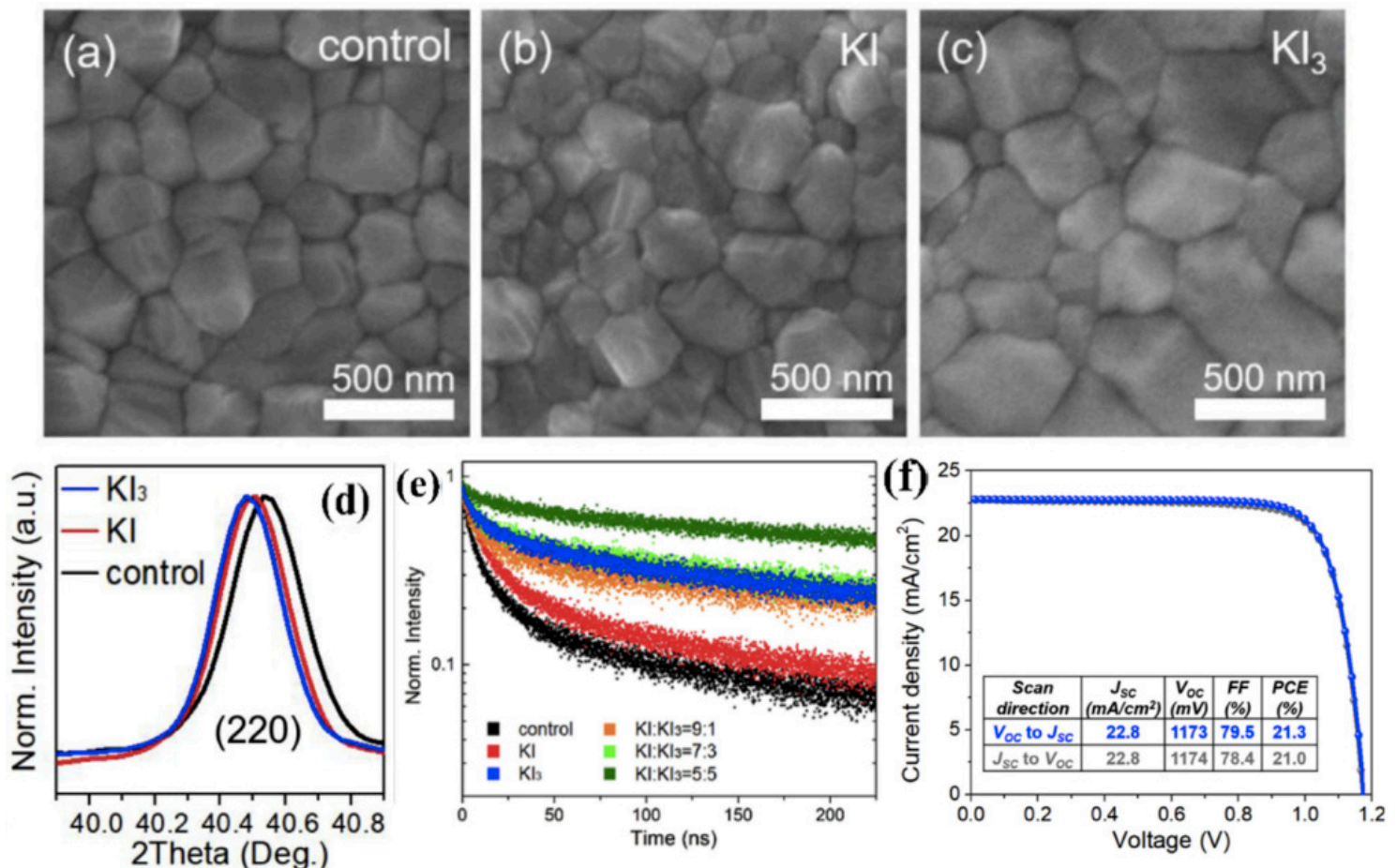

Figure 11. (a) Control, (b) $\mathrm{KI}$ and (c) $\mathrm{KI}_{3}$ SEM images of the addition of a perovskite film. (d) Normalized XRD peaks of the plane of the same perovskite film (220). (e) Time-resolved PL in the absence and absence of $\mathrm{KI}$ additives, $\mathrm{KI}_{3}$ additives and mixtures of $\mathrm{KI}$ and $\mathrm{KI}_{3}$ additives. (f) $\mathrm{J}-\mathrm{V}$ curve of the best performing device for reverse scan and forward scan. Reproduced with permission from Reference [45]. Copyright 2019 Elsevier B.V.

Recently, many studies have passed through additive engineering to passivate grain boundaries (GBs) to produce high quality perovskite film. Fu et al. [46] prepared a high performance PSC incorporating a lead salt of pyridine-2-carboxylate $\left(\mathrm{PbPyA}_{2}\right)$. Pyridine and carboxyl groups on $\mathrm{PbPyA}_{2}$ not only control crystallization, but also passivate GBs to form high quality perovskite film with larger grains and fewer defects. As shown in Figure 12a, during the film formation process, the carboxyl group of $\mathrm{PbPyA}_{2}$ has a strong interaction with $\mathrm{Pb}^{2+}$ and $\mathrm{MA}^{+}$ions, thereby controlling the crystallization of the perovskite to suppress the formation of morphological defects. After crystallization, $\mathrm{PbPyA}_{2}$ molecules are mainly distributed around GBs, not only by organic acid ions interacting with GBs, but also excess $\mathrm{Pb}^{2+}$ ions near GBs can also cover volatile components, thereby reducing deep defects, inhibiting ion migration, and inhibiting the components to volatilize and inhibit external damage. In order to test the effect of $\mathrm{PbPyA}_{2}$ on the crystal structure of perovskite film, the authors conducted $X$-ray diffraction(XRD) tests on films with different doping concentrations, and the results of those tests are shown in Figure 12b. At different concentrations, the diffraction pattern of the tetragonal crystal showed the same, while the doped film showed a peak of $\mathrm{PbPyA}_{2}$ at 9.18, indicating that $\mathrm{PbPyA}_{2}$ was not embedded in the perovskite crystal lattice and was only distributed around GB. A device having the structure shown in Figure 12c was then fabricated, and the J-V curve is indicated in Figure 12d. Clearly, after the introduction of $\mathrm{PbPyA}_{2}$, the device exhibited lower hysteresis and increased $V_{o c}$, indicating that the additive $\mathrm{PbPyA}_{2}$ minimized trap density and inhibited ion migration. The result was a $V_{o c}$ of $1.12 \mathrm{~V}$, a $J_{s c}$ of $22.99 \mathrm{~mA} \mathrm{~cm}^{-2}$, an FF of $77.51 \%$ and a PCE of $19.96 \%$. 

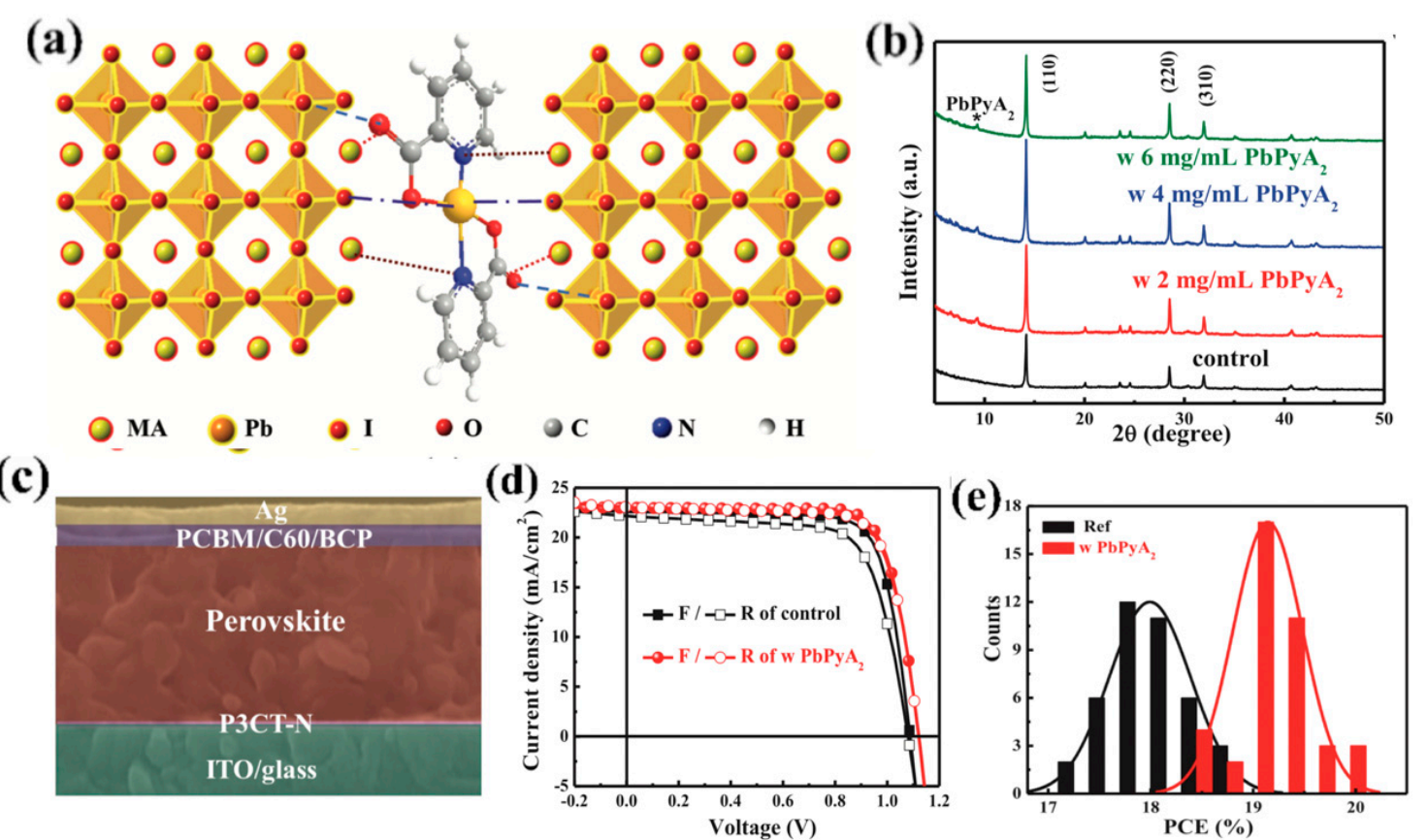

Figure 12. (a) Schematic representation of the PbPyA2 molecule at grain boundaries (GBs) after film formation and strongly interacting with the perovskite component to passivate GBs. (b) XRD patterns of various dopant concentrations and b) SEM images. (c) A cross-sectional view of the PSC device. (d) J-V curve of the device of the undoped and doped film. (e) Repeatability analysis of the device power conversion efficiency (PCE). Reproduced with permission from Reference [46]. Copyright 2019 Wiley-VCH.

Various additives engineering reports are based on $\mathrm{Pb}$-based perovskites. However, in recent years, Sn-based perovskites, which are non-toxic and have a suitable band gap, have also become promising candidates for the preparation of perovskite solar cells. However, the preparation of highly stable and highly efficient tin-based PSCs is challenging, because $\mathrm{Sn}^{2+}$ in perovskites is readily oxidized to $\mathrm{Sn}^{4+}$ upon exposure to air. Tai et al. [47] reported the production of air-stable $\mathrm{FASnI}_{3}$ solar cells by adding hydroxy benzene sulfonic acid or a salt as an antioxidant to the perovskite precursor solution and excess $\mathrm{SnCl}_{2}$. Figure 13a shows the molecular structure of three representative additives used in their work, including phenomenally acid (PSA), 2-aminophenol-4-sulfonic acid (APSA) and hydroquinone sulfonate potassium salt (KHQSA). The interaction between the sulfonate group and the $\mathrm{Sn}^{2+}$ ion causes the perovskite particles and the $\mathrm{SnCl}_{2}$ additive composite layer to be encapsulated in situ, thereby greatly enhancing the oxidative stability of the perovskite film. Compared with the former two, KHQSA containing two hydroxyl $(-\mathrm{OH})$ groups has higher antioxidant activity. Figure $13 \mathrm{~b}$ appears in a scanning transmission electron microscope (STEM) image showing the distribution of KHQSA on the surface of the perovskite particles. Figure 13c shows a XRD pattern of a FASnI ${ }_{3}$ film with different additives. The additive did not cause a significant change in the pattern, indicating that the additive molecules were not incorporated into the perovskite crystal lattice. As shown in Figure 13d, PCE was observed to have a similar dose dependency for PSA, APSA and KHQSA, which can be attributed to a certain amount of additive to prevent phase separation of $\mathrm{SnCl}_{2}$ and oxidation of perovskite. Excessive additives can significantly reduce photocurrent, because the conductivity of the complex located at the grain boundary and surface of the perovskite is poor. After optimization, the champion PCEs of PSA, APSA and KHQSA was 5.58\%, 5.16\% and 6.76\%, respectively. Figure 13 e shows the J-V curves for the best performing raw and KHQSA modified PSCs. The hysteresis of KHQSA-PSC is negligible compared to the apparent JV hysteresis shown in the original PSC, which may be linked to the lower trap density of the perovskite film. 
(a)

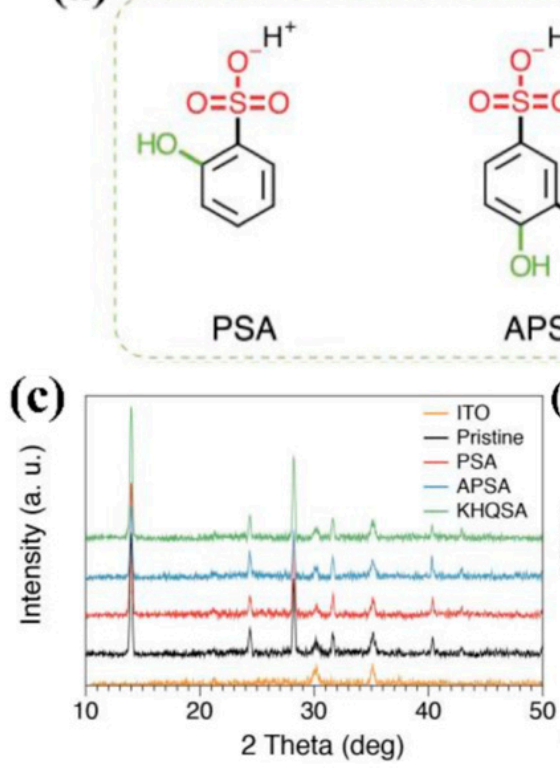

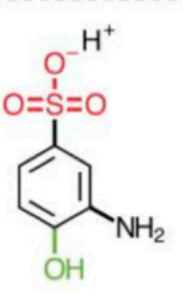

APSA

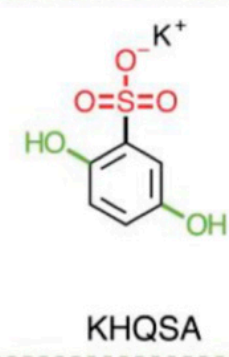

(d)

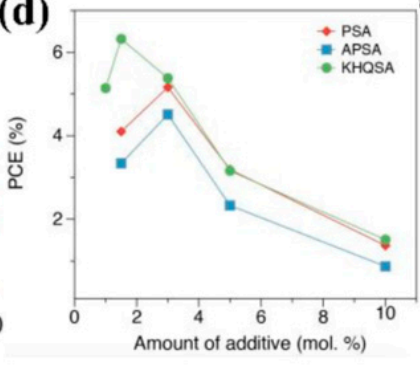

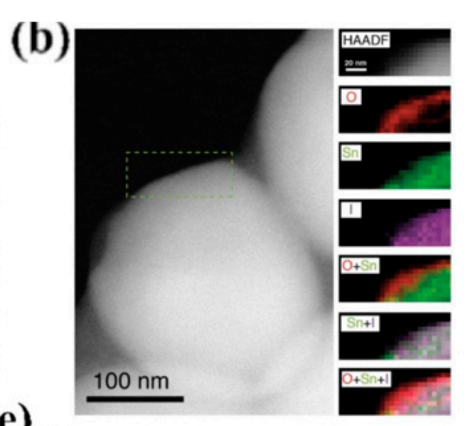

(e) $)_{20}$

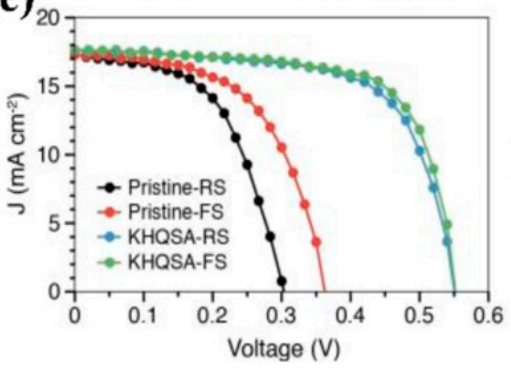

Figure 13. (a) Molecular structure of phenomenally acid (PSA), 2-aminophenol-4-sulfonic acid (APSA) and hydroquinone sulfonate potassium salt (KHQSA). (b) Scanning transmission electron microscope-high angle annular dark field (STEM-HAADF) image and Scanning transmission electron microscope-electron energy loss spectroscopy (STEM-EELS) image of O, Sn and I, corresponding to 10\% KHQSA modified Formamidinium tin iodide $\left(\mathrm{FASnI}_{3}\right.$ ) film (without $\mathrm{SnCl}_{2}$ ). The X-ray photoelectron spectroscopy (XPS) S 2p spectrum was measured from the surface and the entire surface of a $1.5 \%$ KHQSA modified FASnI3 film. (c) XRD patterns of pristine, 3\% PSA, 3\% APSA and 1.5\% KHQSA modified FASnI3 membranes. (d) PCE dose dependence of FASnI3-based PSCs with different amounts of PSA, APSA and KHQSA additives. (e) J-V curves of the pristine and KHQSA modified FASnI3 solar cells. Ref. [47] Reproduced with permission from ref 47. Copyright 2019 Wiley-VCH.

The synergy between different additives has also been explored. Kim et al. [48] reported that the perovskite solar cell of $\left(\mathrm{FA}_{0.65} \mathrm{MA}_{0.2} \mathrm{Cs}_{0.15}\right) \mathrm{Pb}\left(\mathrm{I}_{0.8} \mathrm{Br}_{0.2}\right)_{3}$ was highly efficient by the two complementary additives Phenethylammonium Iodide(PEAI) and $\mathrm{Pb}(\mathrm{SCN})_{2}$. The coupling of $\mathrm{PEA}^{+}$and Thiocyanate ion $\left(\mathrm{SCN}^{-}\right)$provides a synergistic effect, reduces the formation of excess $\mathrm{PbI}_{2}$, enhances crystallinity and enhances the quality of the perovskite film finally. Figure 14a compares SEM images of perovskite films prepared without and with additives, with $2 \% \mathrm{~Pb}(\mathrm{SCN})_{2}$ resulting in significant growth of apparent grains compared to the original film. However, use of $1 \%$ of PEAI reduces the apparent grain size due to the larger size of the PEA, which limits or alters the growth of the 3D perovskite. Figure 14b compares the XRD patterns of the same sample as shown in Figure 14a. Use of PEAI and $\mathrm{Pb}(\mathrm{SCN})_{2}$ increased the main XRD perovskite peak by nearly 14 times compared to the original sample. One potential problem with the $\mathrm{Pb}(\mathrm{SCN})_{2}$ additives is the formation of excess $\mathrm{PbI}_{2}$. A slight excess of $\mathrm{PbI}_{2}$ is generally advantageous over a short period of time. However, excessive $\mathrm{PbI}_{2}$ is generally not conducive to PSC performance. It can also be observed from Figure $14 \mathrm{~b}$ that the formation of such $\mathrm{PbI}_{2}$ is markedly suppressed when $\mathrm{PEAI}$ and $\mathrm{Pb}(\mathrm{SCN})_{2}$ are simultaneously added. Strong molecular interaction between PEAI and $\mathrm{PbX}_{2}(\mathrm{X}=\mathrm{I}$ or SCN$)$ is a good explanation for this. At the same time, as shown in Figure $14 \mathrm{~d}$, defects associated with insufficient lead coordination or halide vacancies may be passivized by SCN located at or near the GB. Figure $14 \mathrm{c}$ shows the J-V curve for the various devices mentioned above. The synergistic effect of using both PEAI and $\mathrm{Pb}(\mathrm{SCN})_{2}$ is evident in dramatically improved device characteristics, with PCE increasing from $16.3 \%$ to $18.7 \%$, an increase of more than $2 \%$. 


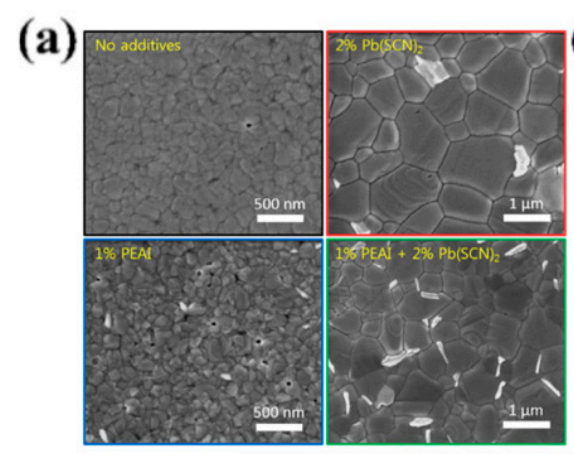

(d)
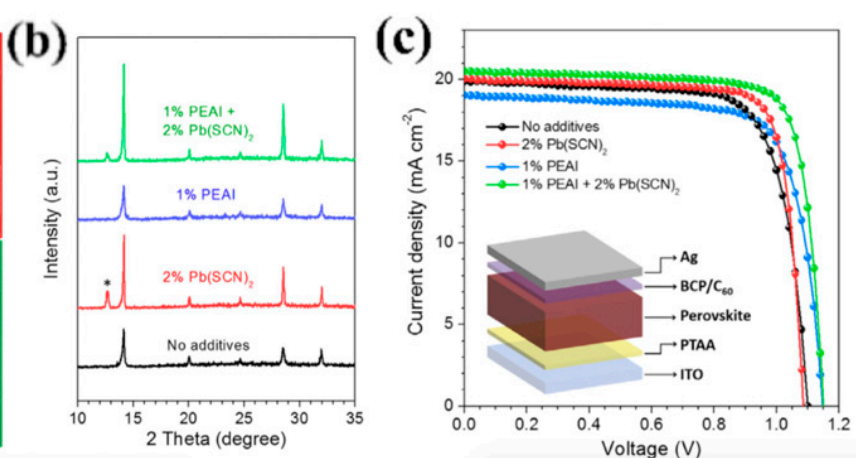

$2 \mathrm{D} /$ quasi $2 \mathrm{D}$

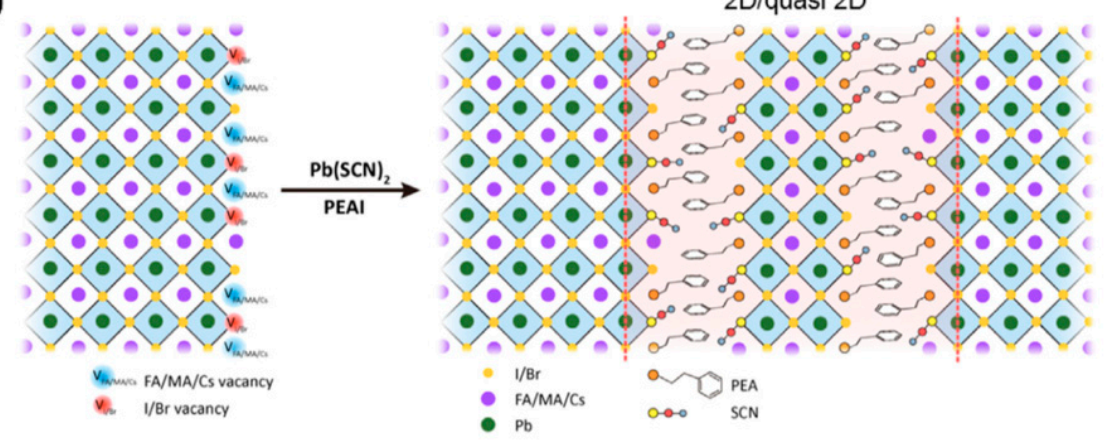

Figure 14. SEM image (a) and XRD pattern (b) of a perovskite film. The symbol * indicates a peak associated with $\mathrm{PbI}_{2}$. (c) J-V curve. The illustration shows the device stack: ITO/ poly(triarylamine) (PTAA)/Perovskite/C 60 / bathocuproine(BCP)/Ag. (d) Schematic representation of passivation defects in perovskites from PEAI's PEA + and $\mathrm{Pb}(\mathrm{SCN})_{2} \mathrm{SCN}$. Reproduced with permission from Reference [48]. Copyright 2019 Cell Press.

\subsection{Forming an Intermediate or Reacting}

While the alkali halide salt additives offer monovalent cations and anions, bivalent or trivalent metal ions have not yet been widely explored as additives. Jahandar et al. [49] used the $\mathrm{CuBr}_{2}$ additive in the perovskite precursor solution to produce devices with a highly efficient. By replacing a part of $\mathrm{PbI}_{2}$ to $\mathrm{CuBr}_{2}$, they fabricated high-efficiency PSCs (ITO/PEDOT: $\left.\mathrm{PSS} / \mathrm{CH}_{3} \mathrm{NH}_{3} \mathrm{I}\left(\mathrm{PbI}_{2}\right)_{1-\mathrm{X}}\left(\mathrm{CuBr}_{2}\right) \mathrm{X} / \mathrm{PCBM} / \mathrm{LiF} / \mathrm{Al}\right)$, and there is no significant $J-V$ hysteresis. The $\mathrm{PbI}_{2}-\mathrm{DMSO}_{2}$ intermediate cannot be flowed due to the melting and resolving process conduct at the same time during the heat treatment, while the $\mathrm{CuBr}_{2}-\mathrm{DMSO}_{2}$ intermediate is flowable [50]. Thus, the $\mathrm{CH}_{3} \mathrm{NH}_{3} \mathrm{I}\left(\mathrm{PbI}_{2}\right)_{1-\mathrm{X}}\left(\mathrm{CuBr}_{2}\right)_{\mathrm{X}}$ perovskite can form larger grains more reproducibly than the $\mathrm{MAPbI}_{3}$ film (Figure 15a-j). Furthermore, the weak bond between DMSO and MAI.PbI2 may accelerate the crystallization of $\mathrm{MAPbI}_{3}$ [51]. Figure $15 \mathrm{k}$ shows the JV curves of $\mathrm{CH}_{3} \mathrm{NH}_{3} \mathrm{I}\left(\mathrm{PbI}_{2}\right)_{1-\mathrm{X}}\left(\mathrm{CuBr}_{2}\right)_{\mathrm{X}}$ perovskite solar cells with various $\mathrm{CuBr}_{2}$ concentration $(\mathrm{x}=0,0.025,0.050,0.075$ and 0.100$)$. The control device had a $V_{o c}$ of $0.945 \mathrm{~V}, J_{s c}$ of $17.96 \mathrm{~mA} / \mathrm{cm}^{2}, F F$ of 0.77 , and PCE of $13.18 \%$. For devices doped with $\mathrm{CuBr}_{2}$, when $\mathrm{x}=0.05, V_{o c}=0.961 \mathrm{~V}, J_{s c}=21.51 \mathrm{~mA} / \mathrm{cm}^{2}, F F=0.82$, and $\mathrm{PCE}=17.09 \%$. Angelis et al. reported the same result, confirming again that Br plays the role as well as iodine in the organometallic halide perovskite [52]. In addition, Mojtaba et al. [53] introduced monovalent cations $\mathrm{Na}^{+}$and $\mathrm{Ag}^{+}$with similar radii of $\mathrm{Pb}^{2+}$ Studies have shown that those additives can minimize the boundaries between the adjacent crystallites and increase charge transport properties and optimize the device performance.

Xiao et al. [54] reported on the important role of $\mathrm{H}_{3} \mathrm{PO}_{2}$ in controlling the morphology of perovskite films, which has been largely ignored. $\mathrm{H}_{3} \mathrm{PO}_{2}$ has been used as a stabilizer in $\mathrm{HI}$, and therefore, introduces $\mathrm{MAH}_{2} \mathrm{PO}_{2}$ impurities into the synthesized MAI (unpurified MAI). $\mathrm{Pb}\left(\mathrm{H}_{2} \mathrm{PO}_{2}\right)_{2}$ mesophase is formed and slows the crystallization processing. Both the $\mathrm{MAH}_{2} \mathrm{PO}_{2}$ impurity and the $\mathrm{Pb}\left(\mathrm{H}_{2} \mathrm{PO}_{2}\right)_{2}$ mesophase all impede the rapid reaction of $\mathrm{PbI}_{2}$ and $\mathrm{MAI}$, resulting in a highly uniform and smooth perovskite film with larger grain size. The authors used non-purified MAI and purified MAI precursor solutions to fabricate the perovskite film by a two-step processing. The perovskite film is formed on 
the ITO/PEDOT:PSS substrate, non-purified MAI with a mirror-like surface, as shown in Figure 16a. The grain size of perovskite film made with purified MAI is not uniform and has many white spots, as shown in Figure 16b. Therefore, $\mathrm{MAH}_{2} \mathrm{PO}_{2}$ will lead to differences morphology of the film. It is worth noting that the conversion from $\mathrm{Pb}\left(\mathrm{H}_{2} \mathrm{PO}_{2}\right)_{2}$ to perovskite by thermal annealing is much slower than the direct reaction of $\mathrm{PbI}_{2}$ and MAI. Therefore, the mesophases of $\mathrm{Pb}\left(\mathrm{H}_{2} \mathrm{PO}_{2}\right)_{2}$ and $\mathrm{MAH}_{2} \mathrm{PO}_{2}$ would coexist. The similar phenomenon has also been explored in existence of $\mathrm{HPbI}_{3}$ [55]. As shown in Figure 16, the performance of the device with $2 \mathrm{wt} . \% \mathrm{MAH}_{2} \mathrm{PO}_{2}$ and the device performance of the non-purified MAI are better than those of the device after purification. In summary, the reaction of $\mathrm{MAH}_{2} \mathrm{PO}_{2}$ and $\mathrm{PbI}_{2}$ is reversible; thus, $\mathrm{Pb}\left(\mathrm{H}_{2} \mathrm{PO}_{2}\right)_{2}$ can be slowly converted to perovskite in the presence of excess MAI during thermal annealing. Based on this finding, the authors controlled the crystallization rate of perovskite by adjusting the proportion of $\mathrm{MAH}_{2} \mathrm{PO}_{2}$ in the MAI precursor to obtain the optimal film morphology.
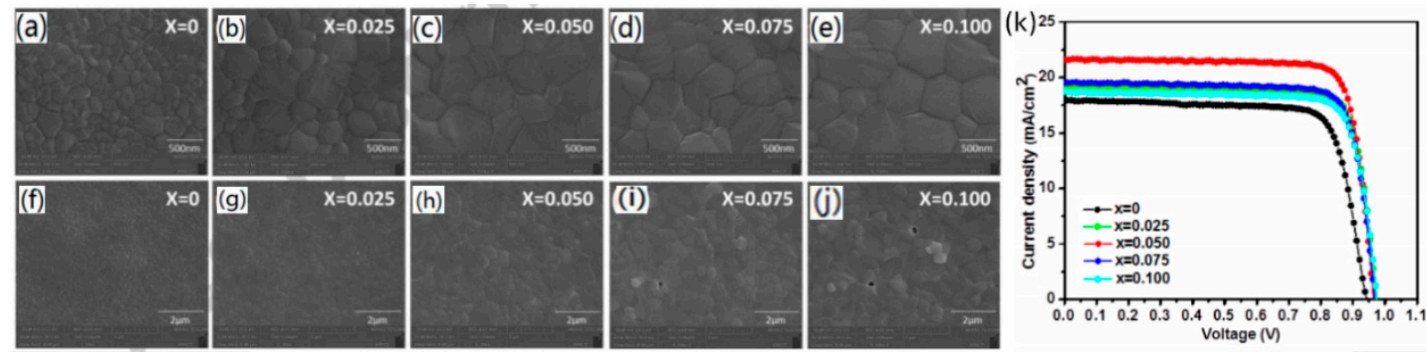

Figure 15. (a-j) top view SEM image of $\mathrm{MAI}\left(\mathrm{PbI}_{2}\right) 1-\mathrm{X}\left(\mathrm{CuBr}_{2}\right) \mathrm{X}$ film with different composition ratios $(x=0,0.025,0.050,0.075$, and 0.100). (k) J-V curve. Reproduced with permission from Reference [49]. Copyright 2016 Elsevier B.V.

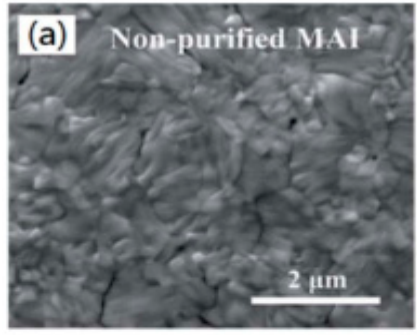

(d)

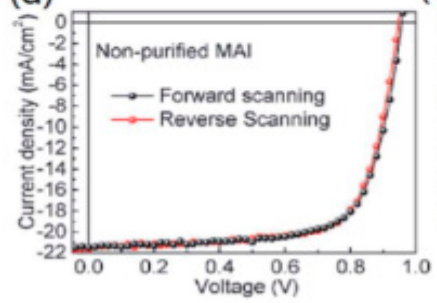

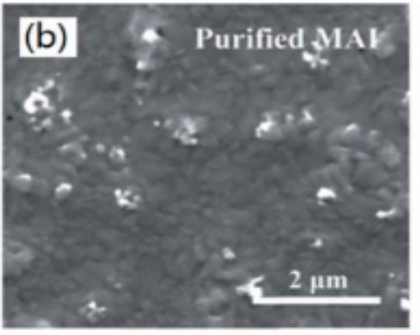

(e)

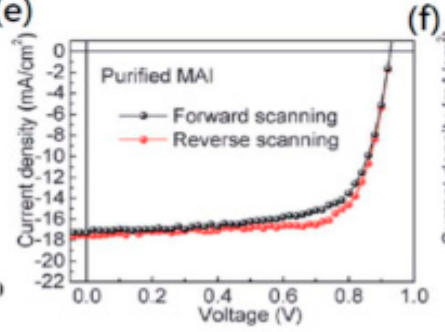

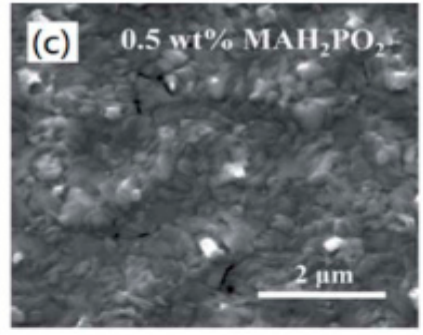

$(\mathrm{f})$

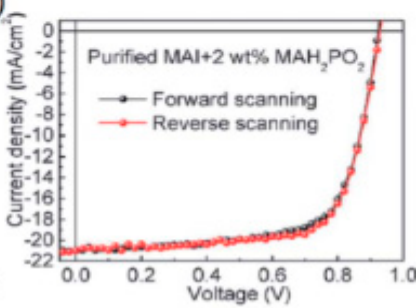

Figure 16. Top view SEM images of films made from: (a) unpurified MAI, (b) purified MAI and (c) purified MAI + 2 wt. $\% \mathrm{MAH}_{2} \mathrm{PO}_{2}$. J-V curve: (d) using non-purified MAI, (e) using purified MAI, and (f) using purified MAI+2 wt. $\% \mathrm{MAH}_{2} \mathrm{PO}_{2}$. [54] Reproduced with permission from Reference [54]. Copyright 2016 Elsevier B.V.

Phosphorous acid (HPA) is also a stabilizer that has been used in PSCs to optimizing film morphology. Zhang et al. [56] showed that the strong reducing agent HPA can act as an additive of a perovskite precursor solution, which is usually added to the HI solution as a stabilizer to prevent the oxidation [57]. By reducing the non-radiative recombination center, the performance of the PSCs is greatly improved. It is well known that a semiconductor device with high performance usually requires high purity and low defect materials. However, due to the obvious non-uniformity of the polycrystalline material and little knowledge of the defect components [58], there is still a good prospect 
for further improvement [59]. MAI has strongly hygroscopicity and is not stable in air and light, especially after long-term storage. The SEM image of perovskite film is shown in Figure 17a,b; both samples show complete coverage without pinholes on the substrate. The perovskite grain size is significantly increased by added HPA, increasing from an average of 168 to $769 \mathrm{~nm}$. As shown in Figure 17c, the photoluminescence (PL) spectra of the perovskite films was found that the HPA-modified perovskite films showed a PL quantum efficiency (PLQE) improvement of $11.6 \pm 0.7 \%$, compared with $0.84 \pm 0.15 \%$ in the control group. It is worth noting that because the HPA additive can reduce the oxidized $\mathrm{I}_{2}$ (Figure 17d) and reduced the density of metal lead in the perovskite crystals result in a PCE improvement from $13.2 \%$ to $16.2 \%$.
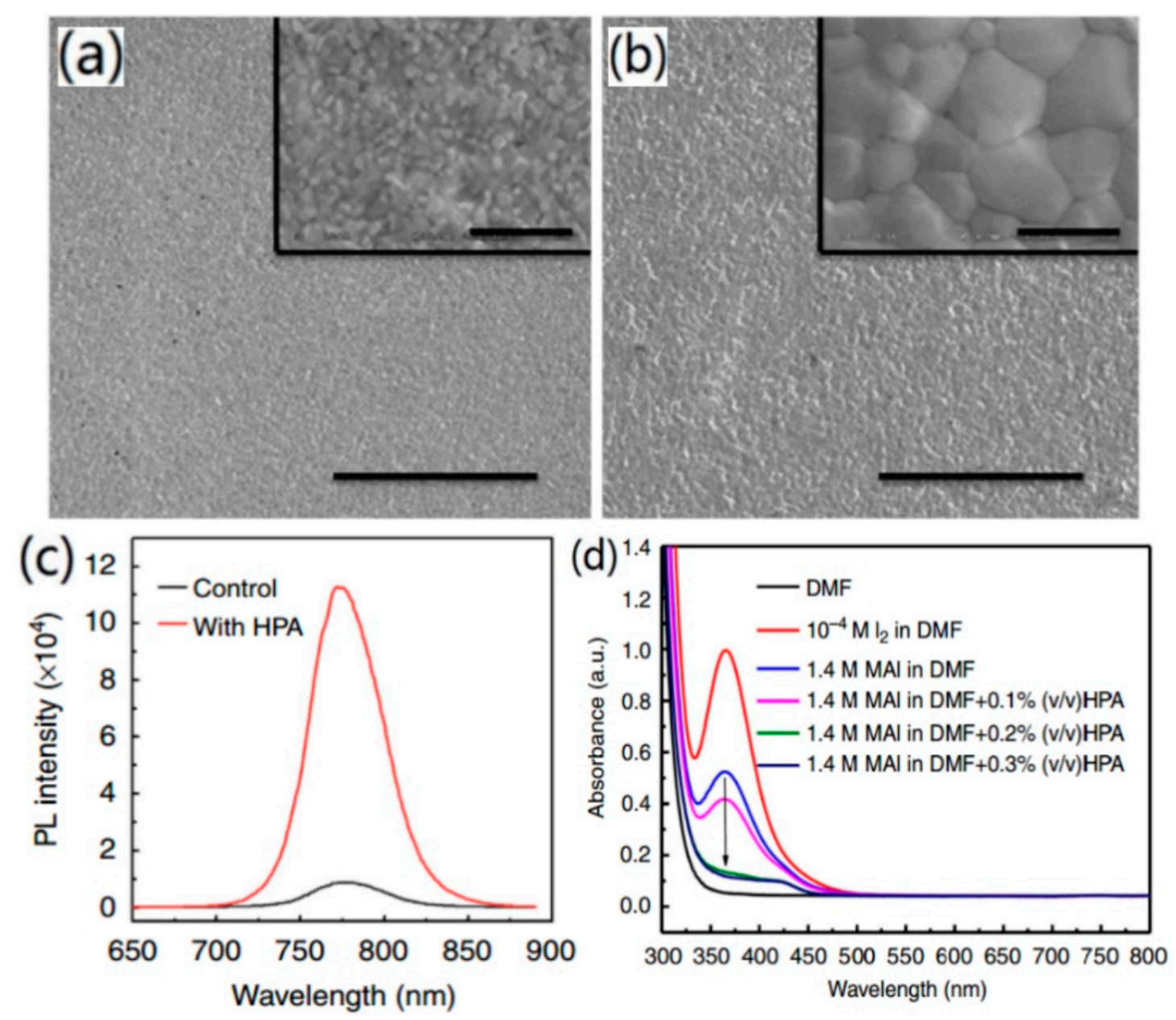

Figure 17. Top view SEM images of the perovskite film: (a) undoped phosphorous acid (HPA), (b) doped with HPA. The scale in the image is $20 \mu \mathrm{m}$ and $1 \mu \mathrm{m}$ in the insets. (c) photoluminescence (PL) spectrum of a perovskite film on glass. (d) Ultraviolet-visible (UV-vis) absorption spectrum of MAI or $\mathrm{I}_{2}$ dissolved in $\mathrm{N}, \mathrm{N}$-Dimethylformamide(DMF) and absorption quenching by addition of HPA-containing MAI solution. Reproduced with permission from Reference [56]. Copyright 2015 Nature Publishing Group.

Recently, Bae et al. [60] proposed a dual additive method in which the morphology of the perovskite film was improved by the simultaneous addition of dimethyl sulfoxide (DMSO) and methoxy ammonium salt (MeO) (Figure 18a). They show that an appropriate amount of $\mathrm{MeO}$ additive can help the precursor form a stable intermediate $\mathrm{PbI}_{2}-\mathrm{DMSO}$ adduct during film formation and expand the perovskite grains by preventing the kinetics of adduct conversion to perovskite. As shown in the film plane of SEM of Figure 18b, when the amount of the MeO additive was increased from 0 to 5 and $10 \%$, the grain size was observed to increase from approximately $150 \mathrm{~nm}$ to $380 \mathrm{~nm}$ and 
$120 \mathrm{~nm}$, respectively. This may be due to the delayed conversion of the adduct of the perovskite caused by the lesser influence of the $\mathrm{MeO}$ additive, resulting in grain growth. However, higher amounts of $\mathrm{MeO}$ did not result in a further increase in grain size. The author attributes this phenomenon to the decomposition of MAI (Figure 18c). Since non-stoichiometric conditions result in a decrease in MAI content, grain growth of perovskites is limited and access $\mathrm{PbI}_{2}$ precipitates in the grain boundaries. As shown in the XRD pattern of Figure 18d, all films exhibited similar diffraction patterns, which mean that $\mathrm{MeO}$ does not affect lattice parameters and crystal structure by substituting the position of the MA cation. The J-V curve of the PSC prepared by various doping amounts of $\mathrm{MeO}$ is illustrated in Figure 18e. When a small amount of $\mathrm{MeO}(\mathrm{MeO} 5$ and $\mathrm{MeO} 10)$ was added, all equipment parameters were enhanced, especially for MeO10 devices with $16.86 \%$ PCE $\left(V_{O C}=1.10 \mathrm{~V}, J_{S C}=21.59 \mathrm{~mA} \mathrm{~cm}^{-2}\right.$ and $F F=0.71$ ).
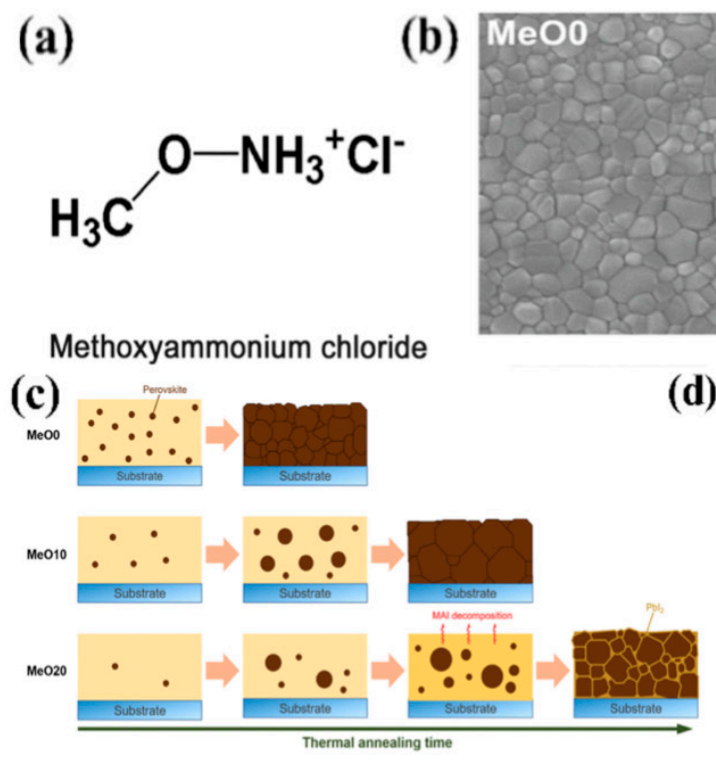

(d)
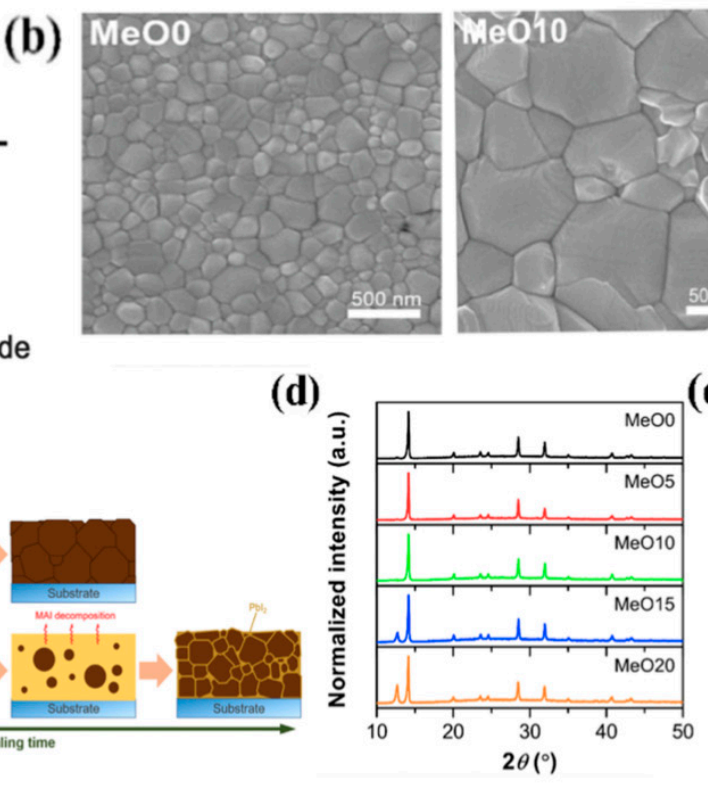
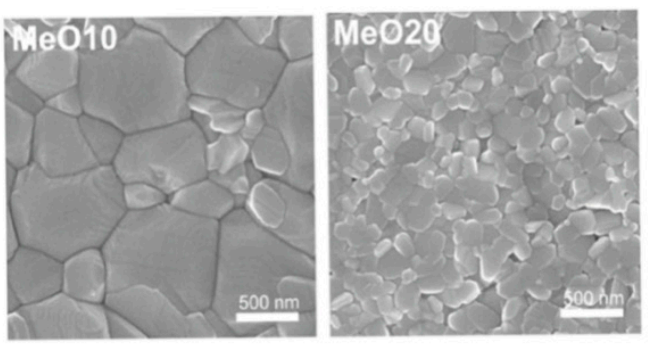

(e)

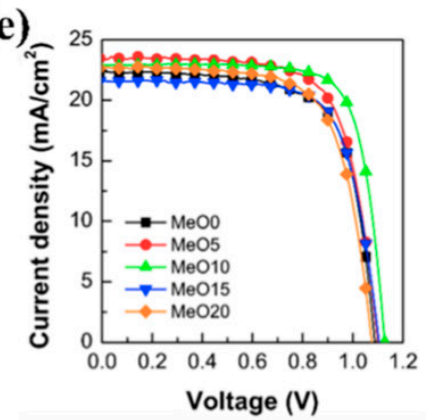

Figure 18. (a) Chemical structure of the MeO additive. (b) SEM images of perovskite films prepared using $\mathrm{MeO}$, MeO10 and MeO20. (c) Schematic representation of the formation of a $\mathrm{MAPbI}_{3}$ film using different amounts of $\mathrm{MeO}$ additive during the annealing process. (d) XRD patterns of films prepared using different amounts of $\mathrm{MeO}$ additives. (e) J-V curve of PSC using five different amounts of $\mathrm{MeO}$ additive. Reproduced with permission from Reference [60]. Copyright 2019 Wiley-VCH.

The method of reducing the crystallization rate by forming an intermediate phase continues being explored. Yang et al. [61] found that ammonium besylate (ABS) can form a mesophase with the precursor material to reduce the crystallization rate. As shown in Figure 19a, the steric hindrance of $\mathrm{ABS}$ and $\mathrm{DMSO}$ hindered the conversion of layered $\mathrm{PbI}_{2}$ to tetragonal phase perovskites. Thereafter, the chlorobenzene accelerated the nucleation and crystallization of the perovskite by rapidly extracting the DMSO solvent, and then formed the MAI-PbI ${ }_{2}-\mathrm{ABS}$ phase. During the annealing process, the mesophase $\mathrm{MAI}-\mathrm{PbI}_{2}-\mathrm{ABS}$ was gradually converted into crystalline $\mathrm{MAPbI}_{3}$, and finally, large-grain and uniform film formed. The decrease in trap density was qualitatively demonstrated by PL (Figure 19b) and time-resolved photoluminescence (TRPL) (Figure 19c) maps, indicating that the surface defects of the film were small. As shown in Figure 19d, the perovskite solar cell has the structure of $\mathrm{FTO} /$ compact titanium dioxide $\left(\mathrm{cTiO}_{2}\right) /$ meso-titanium dioxide $\left(\mathrm{mTiO}_{2}\right) / \mathrm{MAPbI}_{3}$ (with or without ABS)/spiral-OMeTAD/Au. Figure 19e shows photovoltaic performance of various PSCs. In the ABS-based device, the crystallinity is good, the series resistance is small, and the FF is significantly increased from $75.68 \%$ to $78.62 \%$. As a result, the overall PCE has increased dramatically from $17.29 \%$ to an impressive $19.64 \%$. 
(a)

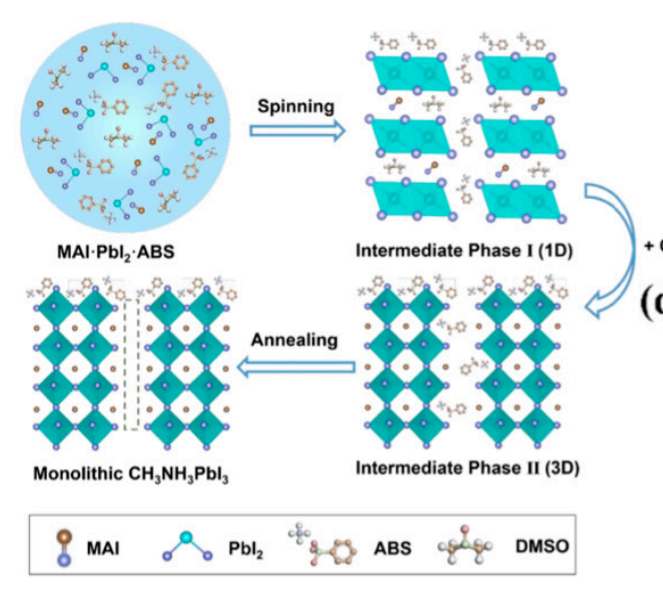

(b)

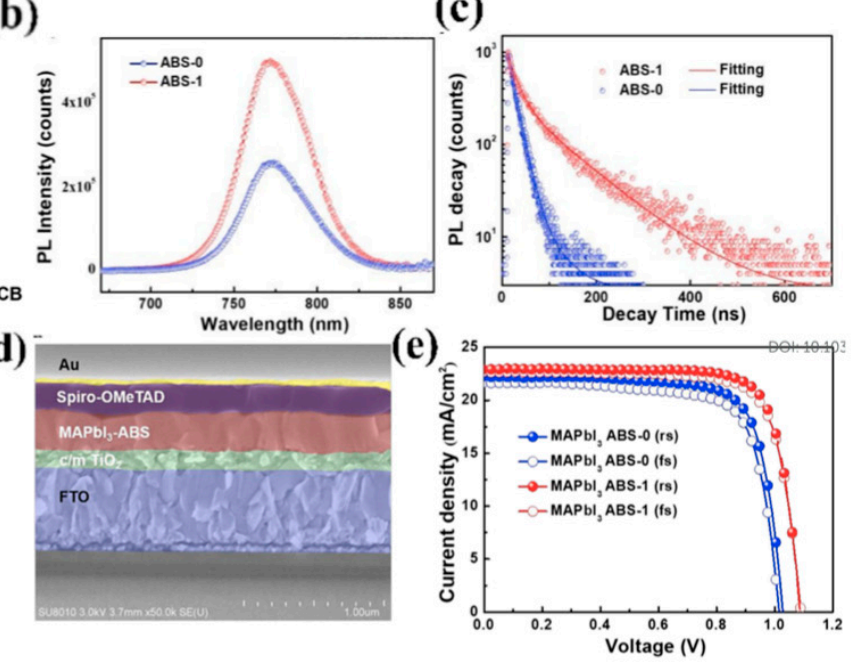

Figure 19. (a) Schematic: crystallization process of perovskite. (b) Single point steady state PL spectra of ABS-0 and ABS-1 films. (c) Single point time-resolved photoluminescence (TRPL) spectrum of ABS-0.

(d) Cross-sectional SEM image of a perovskite film having an optimum concentration of ABS. (e) J-V curve. Reproduced with permission from Reference [61]. Copyright 2019 Royal Society of Chemistry.

The principle of chemical interaction between Lewis acid and Lewis base is also applied to the performance optimization of PSC. Kim et al. [62] used the principle that melamine can interact with Lewis acids such as $\mathrm{PbI}_{2}$, using melaminium dodide (M) as a solution for the perovskite precursor solution. Figure 20a shows the chemical structure of melamine based on 1,3,5-triazine. Since the triamine contains three primary amines, it can interact with a Lewis acid such as $\mathrm{PbI}_{2}$. The bifunctionality of Lewis bases and hydrogen bond acceptors is expected to interact with Lewis acids and organic cations in organic-inorganic halide perovskites to minimize unreacted $\mathrm{PbI}_{2}$. In Figure 20b, the steady state $\mathrm{PL}$ intensity increases after the addition of $\mathrm{M}$, indicating that the additive $\mathrm{M}$ enhances the radiation recombination without changing the optical band gap. In Figure 20c, the PL is exponentially attenuated by two processes of a fast decay component associated with non-radiative recombination and a slow decay component associated with radiation recombination. The carrier lifetime increased from $460.38 \mathrm{~ns}$ to $706.28 \mathrm{~ns}$. The energy level diagram of the material is shown in Figure 20d, with the valence band moving slightly upward by about $0.07 \mathrm{eV}$. In terms of hole injection, the valence band of spiro-MeOTAD is better matched than the control perovskite film. In addition, the upshifted conduction band also facilitates electron injection into the $\mathrm{TiO}_{2}$. Steady-state photoluminescence (PL) and time-resolved photoluminescence (TRPL) were measured to investigate the effect of $\mathrm{M}$ additives on the reorganization and carrier lifetime of the perovskite film. Compared to the original perovskite, the optimized device improved $\mathrm{V}_{\mathrm{OC}}$ and FF, with an average PCE approaching a maximum of $17.32 \%$, an increase of about $9.2 \%$ compared to the PCE of $15.86 \%$ of the original perovskite without additive treatment. 
(a)<smiles>Nc1nc(N)nc(N)n1</smiles>

(d)

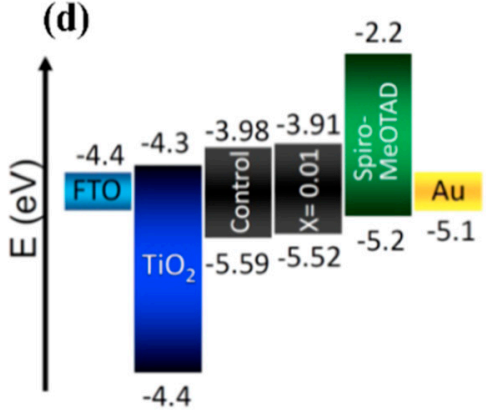

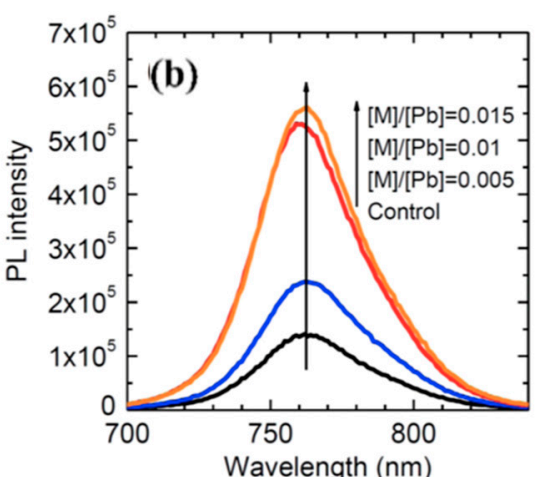

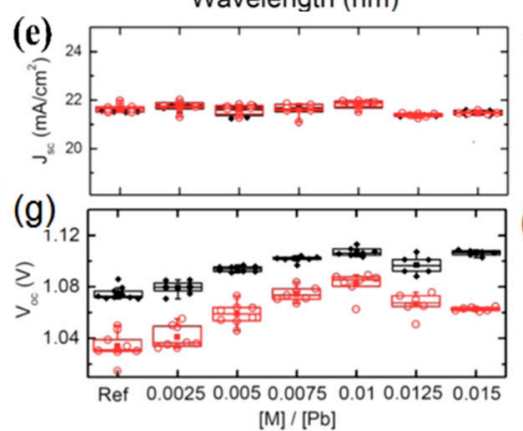

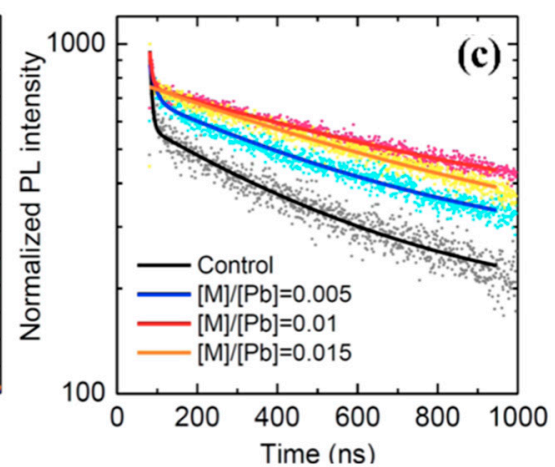

(f)

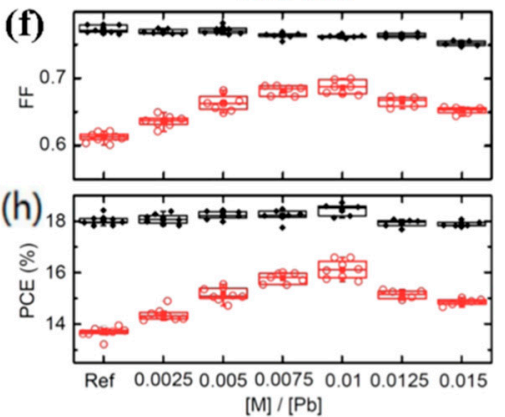

Figure 20. (a) Chemical structure of melamine. (b) PL and (c) TRPL spectra of perovskites. (d) Energy level diagram of the material. (e) Short-circuit current density (JSC), (f) fill factor (FF), (g) open circuit voltage $\left(\mathrm{V}_{\mathrm{OC}}\right)$ and $(\mathbf{h})$ power conversion efficiency $(\mathrm{PCE})$ photovoltaic statistical parameters. Reproduced with permission from Reference [62]. Copyright 2018 American Chemical Society.

Although many chemical additive projects produce high quality film, inherent insulating properties of chemical additives prevent the efficient transport and extraction of charge carriers. Thus, semiconductor additives have been noted. Urea and/or thiourea can be integrated as a core functional part into newly designed semiconductor chemical additives to increase the size and uniformity of the perovskite grains. However, the incorporation of urea or thiourea moieties into organic semiconductors requires a large amount of synthetic effort and often leads to a significant decrease in charge carrier mobility. Therefore, Yu et al. [63] used Rhodamine as a core operative part of semiconductor chemical additives. Furthermore, the effect of the conjugated organic molecule (SA-1, SA-2), which has a rhodamine moiety, as shown in Figure 21a, as a semiconductor chemical additive on the perovskite film formation was further explored. Figure $21 \mathrm{~b}$ shows a SEM image of the resulting perovskite film. It is noteworthy that a significant increase in the perovskite grain size based on $\mathrm{MAPbI}_{3}$ and $\mathrm{FA}_{0.8} \mathrm{MA}_{0.2} \mathrm{~Pb}\left(\mathrm{I}_{0.8} \mathrm{Br}_{0.2}\right)_{3}$ was observed in the film treated with SA-1.This may be due to the Lewis acid-base interaction between the rhodamine fraction of SA- 1 and the perovskite precursor, which may increase the free energy of the critical Gibbs nucleation. Therefore, relatively few nuclei are formed, which leads to a considerable increase in the size of the perovskite grains. The SEM image of the perovskite with SA-2 also showed an increase in the size of the grains, indicating that the tertiary amine moiety did not significantly affect the Lewis acid-base interaction between the rhodamine moiety and the perovskite precursor. Figure 21c shows the J-V curve for the best performance device using SA material. Among them, the PCE with SA-2 was the highest, at $20.3 \%$. 

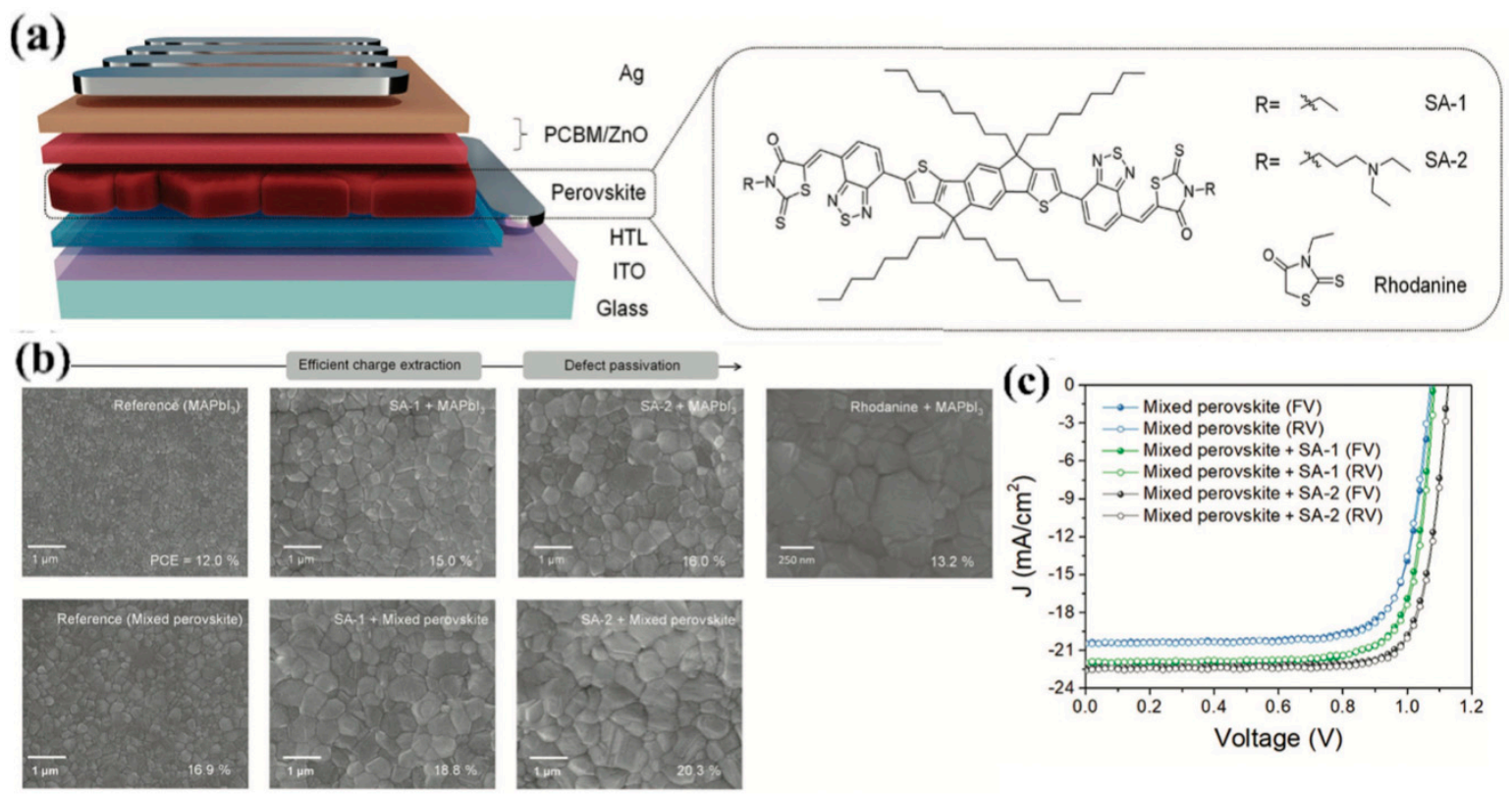

Figure 21. (a) Schematic representation of a PeSC device and chemical structures of SA-1, SA-2 and rhodamine. (b) SEM images of MAPbI3- and $\left(\mathrm{FAPbI}_{3}\right)_{0.8}\left(\mathrm{MAPbBr}_{3}\right)_{0.2}$ (mixed)-based perovskite films without and with SA and rhodamine. (c) J-V characteristics of the PSC without and with SA-1 and SA-2. Reproduced with permission from Reference [63]. Copyright 2019 Wiley-VCH.

\section{Conclusions and Outlook}

In this review, we focused on the main mechanism of the additives in improving the quality of perovskite film in the application of solar cells. Undoubtedly, additive engineering is one of the important aspects in the field of perovskite solar cells. The forces induced by adding various types of additives have been classified and discussed. These weak forces have been demonstrated to improve the quality of the perovskite layer, including the morphology, charge transport and excitonic and optical properties. The comprehensive understanding the role of additives will help people to adopt rational use and design of additives in future. The additive strategies have great potential to improve the PCEs and the long-term stability of the PSCs suitable for commercialization.

Author Contributions: Writing—original draft preparation, J.Y., S.C. and J.X.; writing—review and editing, M.Y., Q.Z., H.L. and Z.L.

Funding: We acknowledge the financial support of the National Nature Science Foundation of China (No. 21402042), Tackling Key Scientific and Technological Problems of Henan Province (No. 192102210173), the Youth Talented Scholars Plan in Universities of Fujian Province and, Science and Technology Program of Longyan (No. LY2018LYF8007).

Conflicts of Interest: The authors declare no conflict of interest.

\section{References}

1. Nayak, P.K.; Cahen, D. Updated assessment of possibilities and limits for solar cells. Adv. Mater. 2014, 26, 1622-1628. [CrossRef] [PubMed]

2. Wadia, C.; Alivisatos, A.P.; Kammen, D.M.; Alivisatos, P. Materials Availability Expands the Opportunity for Large-Scale Photovoltaics Deployment. Environ. Sci. Technol. 2009, 43, 2072-2077. [CrossRef] [PubMed]

3. Soufiani, A.M.; Huang, F.; Reece, P.; Sheng, R.; Ho-Baillie, A.; Green, M.A. Polaronic exciton binding energy in iodide and bromide organic-inorganic lead halide perovskites. Appl. Phys. Lett. 2015, 107, 231902. [CrossRef]

4. Takahashi, Y.; Hasegawa, H.; Takahashi, Y.; Inabe, T. Hall mobility in tin iodide perovskite CH3NH3SnI3: Evidence for a doped semiconductor. J. Solid State Chem. 2013, 205, 39-43. [CrossRef] 
5. Xiao, Z.; Dong, Q.; Bi, C.; Shao, Y.; Yuan, Y.; Huang, J. Solvent Annealing of Perovskite-Induced Crystal Growth for Photovoltaic-Device Efficiency Enhancement. Adv. Mater. 2014, 26, 6503-6509. [CrossRef] [PubMed]

6. $\quad$ Phillips, L.J.; Rashed, A.M.; Treharne, R.E.; Kay, J.; Yates, P.; Mitrovic, I.Z.; Weerakkody, A.; Hall, S.; DuRose, K. Maximizing the optical performance of planar $\mathrm{CH} 3 \mathrm{NH} 3 \mathrm{PbI} 3$ hybrid perovskite heterojunction stacks. Sol. Energy Mater. Sol. Cells 2016, 147, 327-333. [CrossRef]

7. Ponseca, C.S., Jr.; Savenije, T.J.; Abdellah, M.; Zheng, K.; Yartsev, A.; Pascher, T.R.; Harlang, T.; Chabera, P.; Pullerits, T.; Stepanov, A.; et al. Organometal halide perovskite solar cell materials rationalized: ultrafast charge generation, high and microsecond-long balanced mobilities, and slow recombination. J. Am. Chem. Soc. 2014, 136, 5189-5192. [CrossRef]

8. Lin, Z.; Chang, J.; Xiao, J.; Zhu, H.; Xu, Q.H.; Zhang, C.; Ouyang, J.; Hao, Y. Interface studies of the planar heterojunction perovskite solar cells. Sol. Energy Mater. Sol. Cells 2016, 157, 783-790. [CrossRef]

9. Kojima, A.; Teshima, K.; Shirai, Y.; Miyasaka, T. Organometal Halide Perovskites as Visible-Light Sensitizers for Photovoltaic Cells. J. Am. Chem. Soc. 2009, 131, 6050-6051. [CrossRef]

10. Snaith, H.J.; Abate, A.; Ball, J.M.; Eperon, G.E.; Leijtens, T.; Noel, N.K.; Stranks, S.D.; Wang, J.T.W.; Wojciechowski, K.; Zhang, W. Anomalous Hysteresis in Perovskite Solar Cells. J. Phys. Chem. Lett. 2014, 5, 1511-1515. [CrossRef]

11. Eames, C.; Frost, J.M.; Barnes, P.R.F.; O’Regan, B.C.; Walsh, A.; Islam, M.S. Ionic transport in hybrid lead iodide perovskite solar cells. Nat. Commun. 2015, 6, 7497. [CrossRef] [PubMed]

12. Edri, E.; Kirmayer, S.; Cahen, D.; Hodes, G. High Open-Circuit Voltage Solar Cells Based on Organic-Inorganic Lead Bromide Perovskite. J. Phys. Chem. Lett. 2013, 4, 897-902. [CrossRef] [PubMed]

13. Li, F.; Liu, M. Recent efficient strategies for improving the moisture stability of perovskite solar cells. J. Mater. Chem. A 2017, 5, 15447-15459. [CrossRef]

14. Zhou, H.; Chen, Q.; Li, G.; Luo, S.; Song, T.-B.; Duan, H.-S.; Hong, Z.; You, J.; Liu, Y.; Yang, Y. Interface engineering of highly efficient perovskite solar cells. Science 2014, 345, 542-546. [CrossRef]

15. Jeng, J.Y.; Chen, K.C.; Chiang, T.Y.; Lin, P.Y.; Tsai, T.D.; Chang, Y.C.; Guo, T.F.; Chen, P.; Wen, T.C.; Hsu, Y.J. Nickel Oxide Electrode Interlayer in CH3NH3PbI3Perovskite/PCBM Planar-Heterojunction Hybrid Solar Cells. Adv. Mater. 2014, 26, 4107-4113. [CrossRef]

16. Jeon, N.J.; Noh, J.H.; Kim, Y.C.; Yang, W.S.; Ryu, S.; Seok, S.I. Solvent engineering for high-performance inorganic-organic hybrid perovskite solar cells. Nat. Mater. 2014, 13, 897-903. [CrossRef]

17. Xiao, M.; Huang, F.; Huang, W.; Dkhissi, Y.; Zhu, Y.; Etheridge, J.; Bach, U.; Cheng, Y.B.; Spiccia, L.; Gray-Weale, A.; et al. A Fast Deposition-Crystallization Procedure for Highly Efficient Lead Iodide Perovskite Thin-Film Solar Cells. Angew. Chem. Int. Ed. 2014, 53, 9898-9903. [CrossRef]

18. Zuo, F.; Williams, S.T.; Liang, P.W.; Chueh, C.C.; Liao, C.Y.; Jen, A.K.Y. Binary-Metal Perovskites Toward High-Performance Planar-Heterojunction Hybrid Solar Cells. Adv. Mater. 2014, 26, 6454-6460. [CrossRef]

19. McMeekin, D.P.; Sadoughi, G.; Rehman, W.; Eperon, G.E.; Saliba, M.; Hörantner, M.T.; Haghighirad, A.; Sakai, N.; Korte, L.; Rech, B.; et al. A mixed-cation lead mixed-halide perovskite absorber for tandem solar cells. Science 2016, 351, 151-155. [CrossRef]

20. Heo, J.H.; Im, S.H.; Noh, J.H.; Mandal, T.N.; Lim, C.S.; Chang, J.A.; Lee, Y.H.; Kim, H.J.; Sarkar, A.; Nazeeruddin, M.K.; et al. Efficient inorganic-organic hybrid heterojunction solar cells containing perovskite compound and polymeric hole conductors. Nat. Photon. 2013, 7, 486-491. [CrossRef]

21. Jeng, J.Y.; Chiang, Y.F.; Lee, M.H.; Peng, S.R.; Guo, T.F.; Chen, P.; Wen, T.C. CH 3 NH 3 PbI 3 Perovskite/Fullerene Planar-Heterojunction Hybrid Solar Cells. Adv. Mater. 2013, 25, 3727-3732. [CrossRef] [PubMed]

22. Liang, P.W.; Liao, C.Y.; Chueh, C.C.; Zuo, F.; Williams, S.T.; Xin, X.K.; Lin, J.J.; Jen, A.K.Y. Additive Enhanced Crystallization of Solution-Processed Perovskite for Highly Efficient Planar-Heterojunction Solar Cells. Adv. Mater. 2014, 26, 3748-3754. [CrossRef] [PubMed]

23. Chang, C.Y.; Chu, C.Y.; Huang, Y.C.; Huang, C.W.; Chang, S.Y.; Chen, C.A.; Chao, C.Y.; Su, W.F. Tuning Perovskite Morphology by Polymer Additive for High Efficiency Solar Cell. ACS Appl. Mater. Interfaces 2015, 7, 4955-4961. [CrossRef] [PubMed]

24. Zhao, Y.; Wei, J.; Li, H.; Yan, Y.; Zhou, W.; Yu, D.; Zhao, Q. A polymer scaffold for self-healing perovskite solar cells. Nat. Commun. 2016, 7, 10228. [CrossRef] [PubMed] 
25. Wei, J.; Li, H.; Zhao, Y.; Zhou, W.; Fu, R.; Leprince-Wang, Y.; Yu, D.; Zhao, Q. Suppressed hysteresis and improved stability in perovskite solar cells with conductive organic network. Nano Energy 2016, 26, $139-147$. [CrossRef]

26. Guo, Y.; Shoyama, K.; Sato, W.; Nakamura, E. Polymer Stabilization of Lead(II) Perovskite Cubic Nanocrystals for Semitransparent Solar Cells. Adv. Energy Mater. 2016, 6, 1502317. [CrossRef]

27. Roldán-Carmona, C.; Malinkiewicz, O.; Betancur, R.; Longo, G.; Momblona, C.; Jaramillo, F.; Camacho, L.; Bolink, H.J. High efficiency single-junction semitransparent perovskite solar cells. Energy Environ. Sci. 2014, 7, 2968-2973. [CrossRef]

28. Ono, L.K.; Wang, S.; Kato, Y.; Raga, S.R.; Qi, Y. Fabrication of semi-transparent perovskite films with centimeter-scale superior uniformity by the hybrid deposition method. Energy Environ. Sci. 2014, 7, 3989-3993. [CrossRef]

29. Chen, C.C.; Dou, L.; Gao, J.; Chang, W.H.; Li, G.; Yang, Y. High-performance semi-transparent polymer solar cells possessing tandem structures. Energy Environ. Sci. 2013, 6, 2714. [CrossRef]

30. Kim, J.; Kim, S.; Zuo, C.; Gao, M.; Vak, D.; Kim, D. Humidity-Tolerant Roll-to-Roll Fabrication of Perovskite Solar Cells via Polymer-Additive-Assisted Hot Slot Die Deposition. Adv. Funct. Mater. 2019, 29, 1809194. [CrossRef]

31. Mei, A.; Li, X.; Liu, L.; Ku, Z.; Liu, T.; Rong, Y.; Xu, M.; Hu, M.; Chen, J.; Yang, Y.; et al. A hole-conductor-free, fully printable mesoscopic perovskite solar cell with high stability. Science 2014, 345, 295-298. [CrossRef] [PubMed]

32. Mercier, N. (HO2C (CH2)3 NH3)2(CH3NH3) Pb2I7: a predicted non-centrosymmetrical structure built up from carboxylic acid supramolecular synthons and bilayer perovskite sheets. CrystEngComm 2005, 7, 429-432. [CrossRef]

33. Lin, C.T.; De Rossi, F.; Kim, J.; Baker, J.; Ngiam, J.; Xu, B.; Pont, S.; Aristidou, N.; Haque, S.A.; Watson, T.; et al. Evidence for surface defect passivation as the origin of the remarkable photostability of unencapsulated perovskite solar cells employing aminovaleric acid as a processing additive. J. Mater. Chem. A 2019, 7, 3006-3011. [CrossRef]

34. Tang, G.; You, P.; Tai, Q.; Wu, R.; Yan, F. Performance Enhancement of Perovskite Solar Cells Induced by Lead Acetate as an Additive. Sol. RRL 2018, 2, 1800066. [CrossRef]

35. Zhu, K.; Cong, S.; Lu, Z.; Lou, Y.; He, L.; Li, J.; Ding, J.; Yuang, N.; Rümmeli, M.H.; Zou, G. Enhanced perovskite solar cell performance via defect passivation with ethylamine alcohol chlorides additive. J. Power Sources 2019, 428, 82-87. [CrossRef]

36. Tripathi, N.; Shirai, Y.; Yanagida, M.; Karen, A.; Miyano, K. Novel Surface Passivation Technique for Low-Temperature Solution-Processed Perovskite PV Cells. ACS Appl. Mater. Interfaces 2016, 8, 4644-4650. [CrossRef]

37. He, Z.; Zhang, C.; Xu, X.; Zhang, L.; Huang, L.; Chen, J.; Wu, H.; Cao, Y. Largely Enhanced Efficiency with a PFN/Al Bilayer Cathode in High Efficiency Bulk Heterojunction Photovoltaic Cells with a Low Bandgap Polycarbazole Donor. Adv. Mater. 2011, 23, 3086-3089. [CrossRef]

38. He, Z.; Zhong, C.; Su, S.; Xu, M.; Wu, H.; Cao, Y. Enhanced power-conversion efficiency in polymer solar cells using an inverted device structure. Nat. Photon. 2012, 6, 591-595. [CrossRef]

39. Shao, Y.; Xiao, Z.; Bi, C.; Yuan, Y.; Huang, J. Origin and elimination of photocurrent hysteresis by fullerene passivation in $\mathrm{CH} 3 \mathrm{NH} 3 \mathrm{PbI} 3$ planar heterojunction solar cells. Nat. Commun. 2014, 5, 5784. [CrossRef]

40. Seo, J.Y.; Matsui, T.; Luo, J.; Correa-Baena, J.P.; Giordano, F.; Saliba, M.; Schenk, K.; Ummadisingu, A.; Domanski, K.; Hadadian, M. Ionic liquid control crystal growth to enhance planar perovskite solar cells efficiency. Adv. Energy Mater. 2016, 6, 1600767. [CrossRef]

41. Zhang, W.; Saliba, M.; Moore, D.T.; Pathak, S.K.; Hörantner, M.T.; Stergiopoulos, T.; Stranks, S.D.; Eperon, G.E.; Alexander-Webber, J.A.; Abate, A.; et al. Ultrasmooth organic-inorganic perovskite thin-film formation and crystallization for efficient planar heterojunction solar cells. Nat. Commun. 2015, 6, 6142. [CrossRef] [PubMed]

42. Im, J.H.; Jang, I.H.; Pellet, N.; Grätzel, M.; Park, N.G. Growth of CH3NH3PbI3 cuboids with controlled size for high-efficiency perovskite solar cells. Nat. Nanotechnol. 2014, 9, 927-932. [CrossRef] [PubMed]

43. Boopathi, K.M.; Huang, T.Y.; Budiawan, W.; Mohan, R.; Lin, M.Y.; Lee, C.H.; Ho, K.C.; Chu, C.W. Synergistic improvements in stability and performance of lead iodide perovskite solar cells incorporating salt additives. J. Mater. Chem. A 2016, 4, 1591-1597. [CrossRef] 
44. Wang, Q.; Shao, Y.; Dong, Q.; Xiao, Z.; Yuan, Y.; Huang, J. Large fill-factor bilayer iodine perovskite solar cells fabricated by a low-temperature solution-process. Energy Environ. Sci. 2014, 7, 2359-2365. [CrossRef]

45. Zhang, M.; Bing, J.; Cho, Y.; Li, Y.; Zheng, J.; Lau, C.F.J.; Green, M.A.; Huang, S.; Ho-Baillie, A.W. Synergistic effect of potassium and iodine from potassium triiodide complex additive on gas-quenched perovskite solar cells. Nano Energy 2019, 63, 103853. [CrossRef]

46. Fu, S.; Li, X.; Wan, L.; Wu, Y.; Zhang, W.; Wang, Y.; Bao, Q.; Fang, J. Efficient Passivation with Lead Pyridine-2-Carboxylic for High-Performance and Stable Perovskite Solar Cells. Adv. Energy Mater. 2019, 9. [CrossRef]

47. Tai, Q.; Guo, X.; Tang, G.; You, P.; Ng, T.W.; Shen, D.; Cao, J.; Liu, C.K.; Wang, N.; Zhu, Y. Antioxidant grain passivation for air-stable tin-based perovskite solar cells. Angew. Chem. Int. Ed. 2019, 58, 806-810. [CrossRef]

48. Kim, D.H.; Muzzillo, C.P.; Tong, J.; Palmstrom, A.F.; Larson, B.W.; Choi, C.; Harvey, S.P.; Glynn, S.; Whitaker, J.B.; Zhang, F.; et al. Bimolecular Additives Improve Wide-Band-Gap Perovskites for Efficient Tandem Solar Cells with CIGS. Joule 2019, 3, 1734-1745. [CrossRef]

49. Jahandar, M.; Heo, J.H.; Song, C.E.; Kong, K.J.; Shin, W.S.; Lee, J.C.; Im, S.H.; Moon, S.J. Highly efficient metal halide substituted $\mathrm{CH} 3 \mathrm{NH} 3 \mathrm{I}(\mathrm{PbI} 2)$ 1-X (CuBr 2 ) X planar perovskite solar cells. Nano Energy 2016, 27, 330-339. [CrossRef]

50. Garnovskii, A.D.; Kharisov, B.I. Direct Synthesis of Coordination and Organometallic Compounds; Elsevier: Amsterdam, The Netherlands, 1999.

51. Cowan, S.R.; Roy, A.; Heeger, A.J. Recombination in polymer-fullerene bulk heterojunction solar cells. Phys. Rev. B 2010, 82, 245207. [CrossRef]

52. Mosconi, E.; Amat, A.; Nazeeruddin, M.K.; Grätzel, M.; De Angelis, F. First-Principles Modeling of Mixed Halide Organometal Perovskites for Photovoltaic Applications. J. Phys. Chem. C 2013, 117, 13902-13913. [CrossRef]

53. Abdi-Jalebi, M.; Dar, M.I.; Sadhanala, A.; Senanayak, S.P.; Franckevičius, M.; Arora, N.; Hu, Y.; Nazeeruddin, M.K.; Zakeeruddin, S.M.; Grätzel, M.; et al. Impact of Monovalent Cation Halide Additives on the Structural and Optoelectronic Properties of CH3NH3PbI3Perovskite. Adv. Energy Mater. 2016, 6, 1502472. [CrossRef]

54. Xiao, Z.; Wang, D.; Dong, Q.; Wang, Q.; Wei, W.; Dai, J.; Zeng, X.; Huang, J. Unraveling the hidden function of a stabilizer in a precursor in improving hybrid perovskite film morphology for high efficiency solar cells. Energy Environ. Sci. 2016, 9, 867-872. [CrossRef]

55. Wang, F.; Yu, H.; Xu, H.; Zhao, N. HPbI3: A New Precursor Compound for Highly Efficient Solution-Processed Perovskite Solar Cells. Adv. Funct. Mater. 2015, 25, 1120-1126. [CrossRef]

56. Zhang, W.; Pathak, S.; Sakai, N.; Stergiopoulos, T.; Nayak, P.K.; Noel, N.K.; Haghighirad, A.A.; Burlakov, V.M.; Dequilettes, D.W.; Sadhanala, A.; et al. Enhanced optoelectronic quality of perovskite thin films with hypophosphorous acid for planar heterojunction solar cells. Nat. Commun. 2015, 6, 10030. [CrossRef]

57. Robinson, J.M.; Herndon, P.T.; Holland, P.L.; Marrufo, L.D. Regeneration and Recovery of Hydriodic Acid after Reduction of Polyols to Fuels1. Org. Process. Res. Dev. 1999, 3, 352-356. [CrossRef]

58. Kim, H.S.; Lee, C.R.; Im, J.H.; Lee, K.B.; Moehl, T.; Marchioro, A.; Moon, S.J.; Humphry-Baker, R.; Yum, J.H.; Moser, J.E.; et al. Lead Iodide Perovskite Sensitized All-Solid-State Submicron Thin Film Mesoscopic Solar Cell with Efficiency Exceeding 9\%. Sci. Rep. 2012, 2, 591. [CrossRef]

59. Kim, J.; Lee, S.-H.; Lee, J.H.; Hong, K.-H. The Role of Intrinsic Defects in Methylammonium Lead Iodide Perovskite. J. Phys. Chem. Lett. 2014, 5, 1312-1317. [CrossRef]

60. Bae, S.; Jo, J.W.; Lee, P.; Ko, M.J. Controlling the Morphology of Organic-Inorganic Hybrid Perovskites through Dual Additive-Mediated Crystallization for Solar Cell Applications. ACS Appl. Mater. Interfaces 2019, 11, 17452-17458. [CrossRef]

61. Yang, Y.; Peng, H.; Liu, C.; Arain, Z.; Ding, Y.; Ma, S.; Liu, X.; Hayat, T.; Alsaedi, A.; Dai, S. Bi-functional additive engineering for high-performance perovskite solar cells with reduced trap density. J. Mater. Chem. A 2019, 7, 6450-6458. [CrossRef] 
62. Kim, S.G.; Chen, J.; Seo, J.Y.; Kang, D.H.; Park, N.G. Rear-Surface Passivation by melaminium dodide additive for stable and hysteresis-less perovskite solar cells. ACS Appl. Mater. Interfaces 2018, 10, 25372-25383. [CrossRef] [PubMed]

63. Yu, J.C.; Badgujar, S.; Jung, E.D.; Singh, V.K.; Kim, D.W.; Gierschner, J.; Lee, E.; Kim, Y.S.; Cho, S.; Kwon, M.S. Highly efficient and stable inverted perovskite solar cell obtained via treatment by semiconducting chemical additive. Adv. Mater. 2019, 31, 1805554. [CrossRef] [PubMed] article distributed under the terms and conditions of the Creative Commons Attribution (CC BY) license (http://creativecommons.org/licenses/by/4.0/). 